ORIGINAL ARTICLE

\title{
Sequence family variant loss from the AZFc interval of the human $Y$ chromosome, but not gene copy loss, is strongly associated with male infertility
}

\author{
N Machev, N Saut, G Longepied, P Terriou, A Navarro, N Levy, M Guichaoua, C Metzler- \\ Guillemain, P Collignon, A-M Frances, J Belougne, E Clemente, J Chiaroni, C Chevillard, C Durand, \\ A Ducourneau, N Pech, K McElreavey, M-G Mattei, M J Mitchell
}

See end of article for authors' affiliations

Correspondence to:

Correspondence to:
M J Mitchell, Inserm $U$ 491 . Faculté de médecine, 13385 Marseille, France; mitchell@medecine. univ-mrs.fr

Revised version received 14 June 2004

Accepted for publication

16 June 2004

\begin{abstract}
Background: Complete deletion of the complete AZFc interval of the $Y$ chromosome is the most common known genetic cause of human male infertility. Two partial AZFc deletions (gr/gr and bl/b3) that remove some copies of all AZFc genes have recently been identified in infertile and fertile populations, and an association study indicates that the resulting gene dose reduction represents a risk factor for spermatogenic failure.

Methods: To determine the incidence of various partial AZFc deletions and their effect on fertility, we combined quantitative and qualitative analyses of the AZFc interval at the DAZ and CDY1 loci in 300 infertile men and 399 control men.

Results: We detected 34 partial AZFc deletions ( $32 \mathrm{gr} / \mathrm{gr}$ deletions), arising from at least 19 independent deletion events, and found gr/gr deletion in $6 \%$ of infertile and $3.5 \%$ of control men ( $p>0.05$ ). Our data provide evidence for two large AZFc inversion polymorphisms, and for relative hot and cold spots of unequal crossing over within the blocks of homology that mediate gr/gr deletion. Using SFVs (sequence family variants), we discriminate DAZ1/2, DAZ3/4, CDYla (proximal), and CDY1b (distal) and define four types of $D A Z-C D Y 1 \mathrm{gr} / \mathrm{gr}$ deletion.

Conclusions: The only deletion type to show an association with infertility was DAZ3/4-CDYla $(p=0.042)$, suggesting that most $\mathrm{gr} / \mathrm{gr}$ deletions are neutral variants. We see a stronger association, however, between loss of the CDYla SFV and infertility $(p=0.002)$. Thus, loss of this SFV through deletion or gene conversion could be a major risk factor for male infertility.
\end{abstract}

n 1976, the cytogenetic analysis of six azoospermic individuals mapped the AZF (azoospermia factor) locus, which is necessary for normal spermatogenesis, to the distal long arm euchromatin of the human Y chromosome. ${ }^{1}$ It was not until 1992 that molecular analysis confirmed these findings with the discovery of two interstitial deletions situated in this region in azoospermic men. ${ }^{2}$ In 1996, a third, independent, deletion interval was identified and the three intervals were named $A Z F a, A Z F b$, and $A Z F c{ }^{3}$ Subsequent studies have demonstrated that deletions affecting the $A Z F C$ interval are by far the most common, affecting approximately $\mathrm{I}$ in 10 men with idiopathic azoospermia. ${ }^{4-6}$

The first $A Z F C$ candidate gene to be isolated from the $A Z F C$ interval was $D A Z$ (deleted in azoospermia). ${ }^{5} D A Z$ originated on the $\mathrm{Y}$ chromosome as a transposition of a DNA segment containing the autosomal germ-cell specific gene $D A Z L$, and comparative analyses in primates show that the $D A Z$ transposition occurred $\sim 35$ million years ago in a common ancestor of old world monkeys and humans. ${ }^{7}$ There is at least one other functional gene within the $A Z F_{C}$ interval: $C D Y 1$, a retroposon that codes a protein with proven histone acetyltransferase activity. ${ }^{8}$ Although found only in primates, CDY1 is believed to have been retroposed directly into MSY (male specific region of the $Y$ chromosome) from a transcript of the autosomal gene CDYL more than 150 million years ago, making it one of the oldest genes on the Y chromosome. ${ }^{9}$ At present, $D A Z$ and $C D Y I$ are the only transcription units in the $A Z F C$ interval for which there is any evidence that function has been selectively maintained on the Y chromosome.

In almost all cases, deletions of the entire $A Z F C$ interval are associated with infertility characterised by a drastic reduction in sperm count due to the loss of active spermatogenesis from most testicular tubules. Spermatogenesis is completed, but on a very small scale. Most $A Z F c$ deleted men are severely oligozoospermic or azoospermic, but reported sperm counts range from 0 to 7 million per millilitre. There are, nevertheless, rare $A Z F c$ deleted men who have conceived multiple children naturally. ${ }^{10-12}$ All of the sons of these men are infertile. The few spermatozoa produced by most $A Z F c$ deleted men can be successfully used for in vitro fertilisation by ICSI (intracytoplasmic sperm injection). Although $A Z F c$ deleted children conceived by ICSI are generally healthy, it is important to identify the $A Z F C$ genes involved, as this will improve the diagnosis of genetic causes of male infertility, and, thus, allow an informed evaluation of the health risks faced by an ICSI conceived child.

Despite the high frequency of the $A Z F c$ microdeletion, the key genes have not yet been identified. The detection and characterisation of smaller deletions within the $A Z F C$ interval are required, in order to understand how the $A Z F C$ interval contributes to human fertility. Initial evidence that partial $A Z F c$ deletions are present in a small percentage of infertile men came from several groups focusing on either sequence family variant (SFV) or fluorescent in situ hybridisation (FISH) analysis of the DAZ gene. ${ }^{13-15}$ Recently, using locus specific PCR assays and dual colour FISH, a common class of partial deletion was described and was named the gr/gr deletion $(\mathrm{gl} / \mathrm{g} 2, \mathrm{rl} / \mathrm{r} 3, \mathrm{r} 2 / \mathrm{r} 4) .{ }^{16}$ The gr/gr deletion is predicted to

Abbreviations: CEPH, Centre d'étude du polymorphisme humain; FISH, fluorescent in situ hybridisation; ICSI, intracytoplasmic sperm injection; SFV, sequence family variant 
result in the loss of some, but not all, copies of all $A Z F c$ genes. ${ }^{17}$ In that study, gr/gr deletion was found in $3.8 \%$ of infertile men with a sperm count of $<5 \times 10^{6} / \mathrm{ml}$, and $2.2 \%$ of fertile men. However, its absence from a group of 148 normospermic men led to the conclusion that the gr/gr deletion is associated with decreased sperm production resulting from the reduced dose of $A Z F C$ genes. ${ }^{16}$ Here, we present our characterisation of the $A Z F C$ interval in 300 infertile and 399 control men. Using quantitative and qualitative assays, we identified 34 cases of partial $A Z F C$ deletion: 32 lack some copies of both $D A Z$ and $C D Y 1$, while two lack some copies of either $D A Z$ or CDYI.

\section{METHODS \\ Infertile men and controls}

We studied five different groups: (i) 254 individuals with unexplained infertility and reduced or absent sperm counts of $0-5 \times 10^{6}$ spermatozoa $(\mathrm{spz}) / \mathrm{ml}$ (composed of 94 individuals with $0-0.1 \times 10^{6} \mathrm{spz} / \mathrm{ml}, 73$ with $>0.1-1 \times 10^{6} \mathrm{spz} / \mathrm{ml}$, and 87 with $>1-5 \times 10^{6} \mathrm{spz} / \mathrm{ml}$ ); (ii) 46 individuals with unexplained infertility and sperm counts of $5-131 \times 10^{6} \mathrm{spz} / \mathrm{ml}$; (iii) 210 unselected men of unknown fertility status; (iv) 185 fertile men with one or more children; and $(\mathrm{v})$ four normospermic men. Samples were collected using approved protocols and the informed consent of all individuals was obtained. The required approval for this study was obtained from the French committee for the Protection of Persons in Biomedical Research (CCPPRB). The infertile men were drawn from a larger group of 361 individuals recruited from two infertility clinics in Marseilles and one in Toulon, France. For all patients, urogenital examination, karyotype Y microdeletion status, and sperm parameters, according to the criteria of the WHO (World Health Organization), were determined. These analyses allowed us to exclude 61 individuals: 28 obstructive azoospermic cases (including 11 cases of bilateral agenesis of the vas deferens associated with mutations in both alleles of CFTR), 13 47,XXY and one 47,XXY/46,XX/46,XY Klinefelter cases, three $47, X Y Y$ men, 10 unrelated $A Z F c$ deletions, four $A Z F b+c$ deletions, one partial $A Z F b$ deletion, and one $A Z F a$ deletion.

The control samples are mostly from local sources, but include 57 unrelated fathers from CEPH (Centre d'étude du polymorphisme humain) reference families. The unselected men of unknown fertility were anonymous blood donors from the local blood transfusion service (Etablissement Français du Sang Alpes Mediterranée). The proportion of Y haplogroups in the CEPH fathers is similar to our local populations, except for $\mathrm{Hg}-\mathrm{DE}$, which is more frequent in local controls $(9.5 \%-19 \%$ local $v 5 \% \mathrm{CEPH})$. The CEPH father, 142001, with the gr/gr deletion has seven children.

\section{Sequence family variant (SFV) analysis}

We screened for SFVs in $D A Z$ and CDYI. For DAZ, we chose the SFV at the sequence tagged site $\mathrm{SY} 587$ in intron $10,{ }^{18}$ also referred to as "DAZ-SNV V". ${ }^{15}$ The sY587 SFV discriminates $D A Z 1 / 2$ from $D A Z 3 / 4$, and its position outside the intragenic duplications that affect exons 2-8 means that sY587 is present in only one copy per $D A Z$ gene. To confirm the sY587 results, we also sequenced all men with a partial $A Z F c$ deletion for an SFV 93 bp upstream from exon 2 of the $D A Z$ gene. This SFV also differentiates DAZl/2 (A) and DAZ3/4 (G). The results agree with those obtained for sY587. Since the Y chromosome reference sequence shows no SFV within the transcribed portion of the CDYI gene, we used a C/A SFV situated $7750 \mathrm{bp} 5^{\prime}$ of the CDYl translation start codon (CDY1-7750). We also used an SFV that we discovered in the 5' UTR of $C D Y 1$ when sequencing CDY1 in our patients with partial $A Z F C$ deletions, and it was the only polymorphism that we discovered (MJM and EC, unpublished data). SFVs were scored by PCR followed by restriction enzyme digestion ( 2 units for $2 \mathrm{~h}$ ): DAZ sY587, DraI (DAZl/2 cut); CDY1-7750, PvuII (CDYlb cut); and CDY1-84, AluI (CDYla cut). To prevent cross-amplification of CDY2, the CDY1-84 SFV was scored by two rounds of PCR, the first being specific for $C D Y 1$, followed by digestion. The SFV DAZ exon2-93 was scored by sequencing. Primer pairs: sY587, 0912/0913; CDY1-7750, o1025/o1026; DAZ exon2-93, ol226/o1227; CDY1-84, $1^{\circ}$ ol187/ol 188 (30 cycles), $2^{\circ}$ ol 187/ol 195 (10 cycles).

Cases of SFV absence were confirmed by sequencing, and no additional SNPs were detected.

\section{Fluorescent in situ hybridisation}

We performed FISH using the $D A Z$ cosmid $18 \mathrm{E} 8^{18}$ to probe interphase nuclei from lymphoblastoid lines. In the majority of interphase nuclei, which are at Gl, 18E8 gives a single hybridisation signal for each $D A Z$ gene pair present. In most men, where there are two $D A Z$ gene pairs, cosmid 18E8 gives two signals on the majority of interphase nuclei. ${ }^{14}$

FISH was performed on interphase nuclei obtained using standard cytogenetic techniques on non-synchronised lymphoblastoid cell lines. The DAZ cosmid 18E8 was labelled with biotin-14dCTP (Bioprime DNA labelling system, Invitrogen, France), hybridised using a standard protocol and revealed by means of fluorescein isothiocyanateconjugated avidin. Over 100 nuclei were screened for each patient. Nuclei were counterstained with propidium iodide diluted in anti-fade solution. Preparations were observed using an axioplan-2 Zeiss fluorescent microscope and the images were captured with a SenSys CCD camera (Photometrics, Tucson, AZ, USA).

\section{PCR based quantification of copy number}

In order to quantify copy number using PCR, we simultaneously amplified the $A Z F C$ locus to be quantified and a homologous locus outside the $A Z F C$ interval, as an internal standard, using a single primer pair in a standard PCR reaction of 28-32 cycles. The primers flank an insertion/ deletion difference of 3-5 bp, which allowed the products amplified from the $A Z F c$ loci and the control loci to be separated by polyacrylamide gel electrophoresis. One of the primers was labelled at its $5^{\prime}$ end with a fluorochrome (IRDye 800, LI-COR, Lincoln, NE, USA) and the other carried a GTTTCTT tag at its $5^{\prime}$ end. This short tag has been reported to stimulate the Taq polymerase to add an adenosine residue to the end of the complementary (labelled) strand, resulting in the adenylation of almost all labelled fragments. ${ }^{19}$ This overcame the problem of doublet bands caused by heterogeneous adenosine addition, which had initially made quantification difficult. Following PCR, the reaction was mixed with $95 \%$ formamide, denatured at $95^{\circ} \mathrm{C}$ for $5 \mathrm{~min}$, and the different sized loci separated on an automatic sequencer Gene ReadIR 4200 (LI-COR). Quantification was performed by ONE-DScan (Scanalytics, Fairfax, VA, USA).

We developed five quantitative tests of this type. The positions of the loci screened are shown in figs 1 and 2 .

\section{CDY1-cds v CDY2 (primers oMJ953a/o1023)}

There are two identical copies each of CDY1 and CDY2, which share $98 \%$ nucleotide identity. ${ }^{20}$ CDY2 is not affected by the complete $A Z F c$ deletion. We amplified $C D Y 1$ and $C D Y 2$ across a $3 \mathrm{bp}$ indel difference in the coding region, to give fragments of $134 \mathrm{bp}$ for CDY1 and $137 \mathrm{bp}$ for CDY2. All men were screened with this test.

CDY1-9825 v CDY2 (primers o1 207/o1208)

A further CDY test that was used to screen all cases of SFV loss at CDY1-7750. 


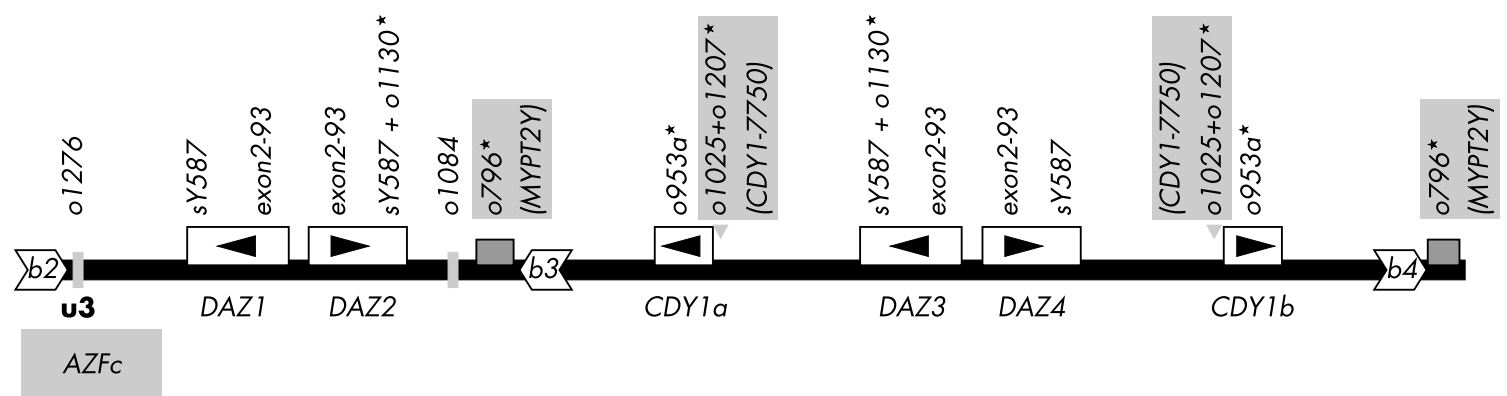

Figure 1A Qualitative and quantitative analyses of the AZFc interval. Schematic representation of the AZFc interval, showing the relative position of the loci analysed. Tests developed in this study are designated by their forward primer (see Methods) and dose tests are indicated with an asterisk.

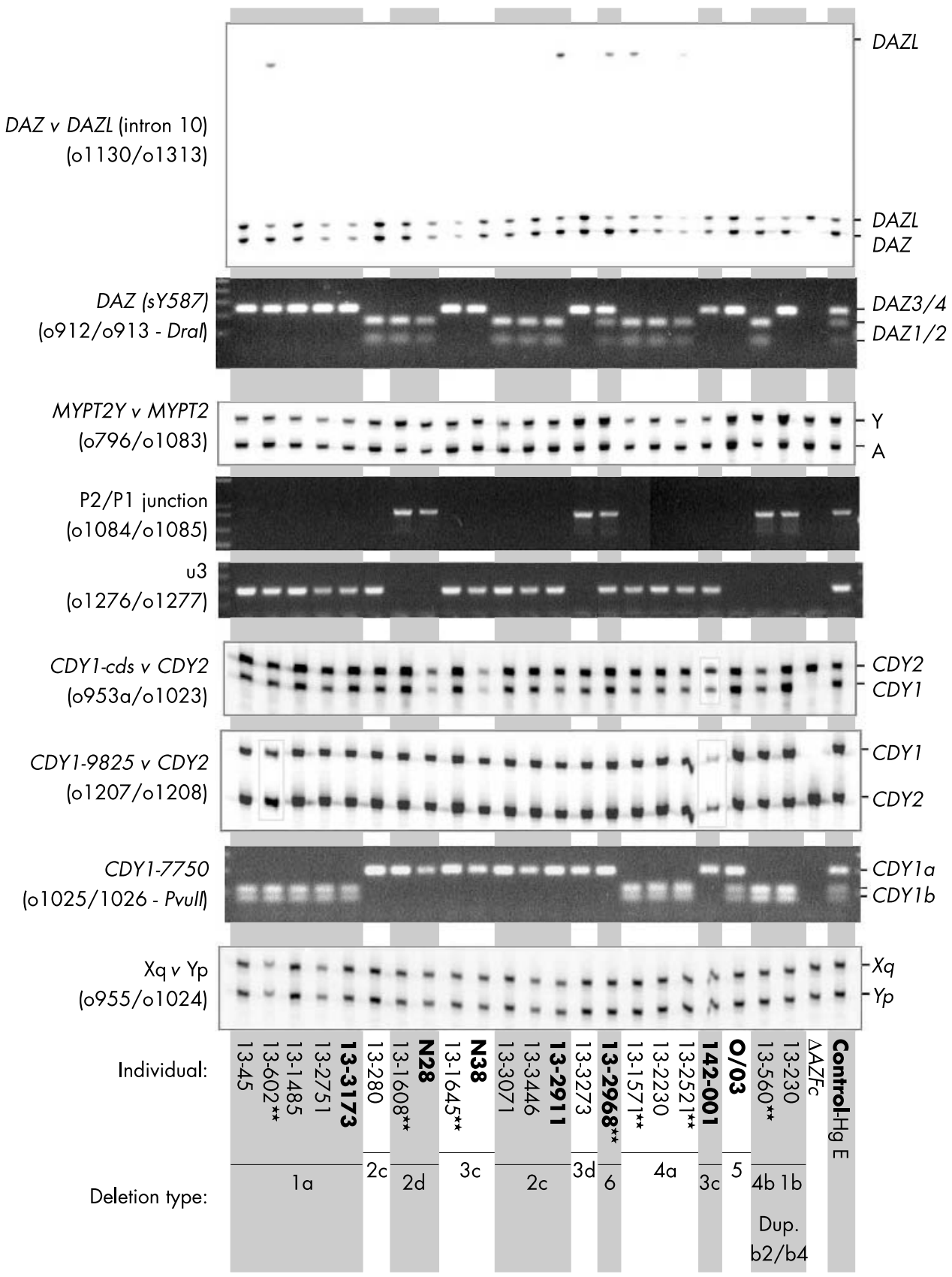

Figure 1B The results obtained with 22 individuals with a partial AZFc deletion are shown, together with a case of b2/b4 deletion (complete AZFc deletion) and an undeleted case. Identifiers of individuals from control populations are shown in bold. **Results confirmed by FISH with DAZ cosmid 18E8. The extra fragment observed in the DAZ v DAZL test corresponds to a 40 bp insertion polymorphism in intron 10 (see Methods). In these cases, the fragments amplified from each DAZL allele have the same intensity. 


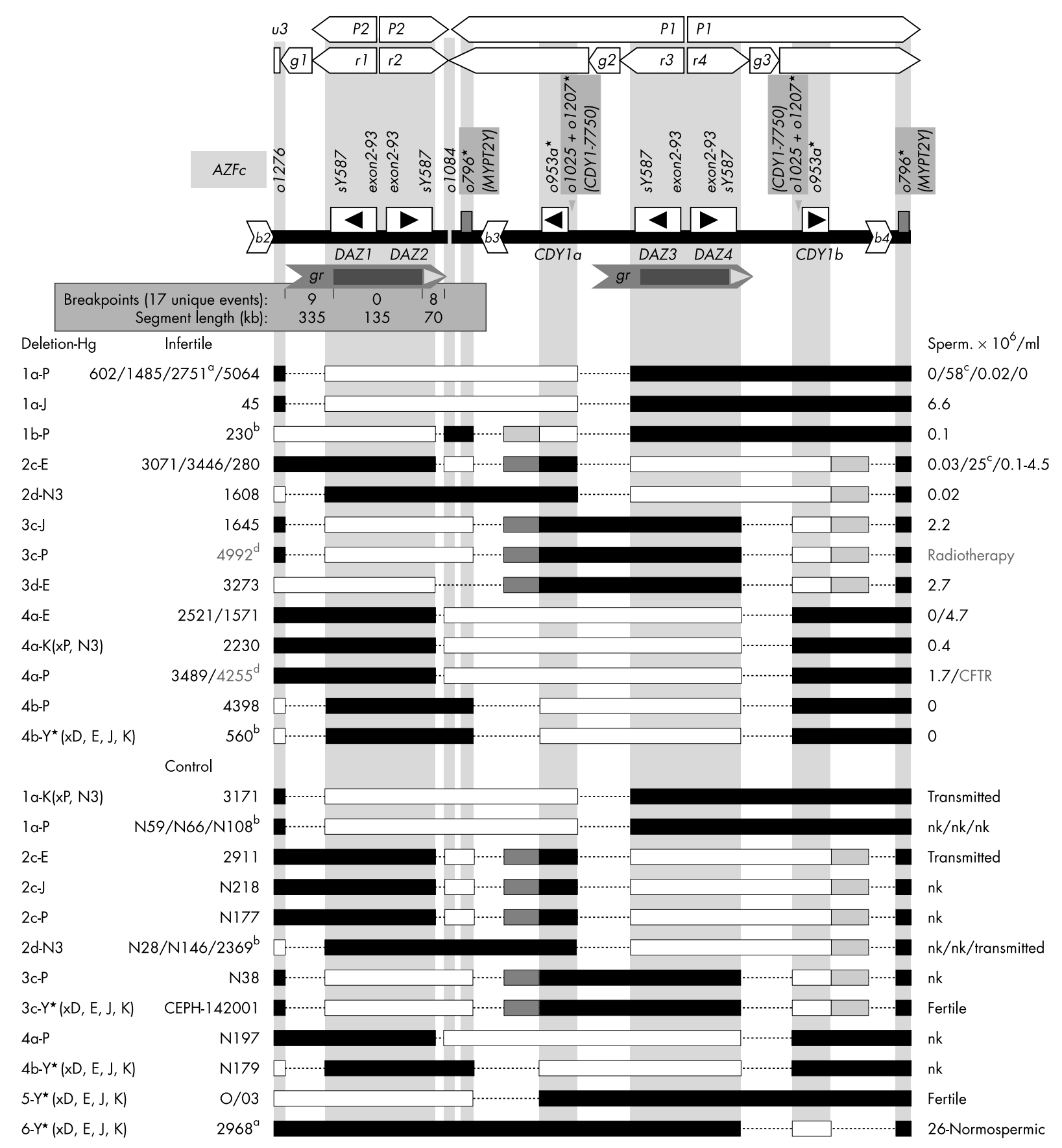

Figure 2 The six types of DAZ/CDY1 partial deletions of the AZFc interval found in the fertile and infertile populations. The deletions are shown relative to a schematic representation of the AZFc interval. ${ }^{4}$ Large arrows, labelled "gr", under the gene map indicate the position of the large direct gr amplicon repeats, between which unequal crossing over is proposed to mediate gr/gr deletions. ${ }^{16}$ No breakpoints were found within the region of the $D A Z$ genes indicated by the dark grey box within the "gr" arrow, whereas the pale grey triangle indicates a hotspot of unequal crossing over. Amplicons b2 and b4 mark the boundaries of the AZFc interval. The various SFVs and copy number tests (*) used in this study are shown above the AZFc gene map. Deleted segments are represented by white bars, and retained segments by black bars. Pale grey and dark grey bars indicate, respectively, that the segment is designated deleted, or retained, based on the assumption that the chromosome carried an inversion polymorphism (fig 4) prior to deletion. The dotted lines represent regions that were not tested directly and whose presence or absence could not be extrapolated from the results obtained with flanking markers. Deletion type 1-6, and inversion type a, b, c, or d (fig 4) are indicated to the left of each deletion, together with the $\mathrm{Y}$ haplogroup and the identifier of the individuals. The sperm count, where known, is shown to the right, in the same order as the identifiers. "nk" means fertility status is not known. "Father has been tested and has the same deletion; "cases of b2/b4 duplication following gr/gr deletion; calthough 13-1485 and 13-3446 produce normal numbers of spermatozoa, 13-1485 showed a moderate asthenospermia and $>90 \%$ teratospermia, while 13-3446 showed a severe asthenospermia and a moderate teratospermia; dindentifiers in grey refer to men who were excluded from the study because they had obstructive azoospermia: 13-4992 (radiotherapy for testicular cancer) and 13-4255 (bilateral agenesis of the vas deferens). Diagram is not to scale. 
$D A Z$ v DAZL (primers o1130/o1313)

In order to dose $D A Z$, we co-amplified a fragment of intron 10 from $D A Z$ and $D A Z L$. This intron contains the SFV at sY587 and is present in one copy per $D A Z$ gene. Thus, from a $46, X Y$ DNA with an intact $A Z F C$ interval, we would expect to amplify four copies of $D A Z$ for every two copies of $D A Z L$ (66\%:33\%). The expected fragment sizes are $184 \mathrm{bp}$ for $D A Z$ and $187 \mathrm{bp}$ for $D A Z L$. When we performed the test, an extra band at $230 \mathrm{bp}$ was observed in 144 out of 575 individuals. We determined, by sequencing, that this fragment results from a $40 \mathrm{bp}$ insertion polymorphism in the DAZL intron 10, since in a given individual it has the same intensity as the $187 \mathrm{bp}$ $D A Z L$ fragment, which has half its expected intensity. Furthermore, there are eight individuals with the $230 \mathrm{bp}$ band who lack the $187 \mathrm{bp} D A Z L$ band altogether, and their observed frequency (0.014) is close to the expected homozygote frequency $(0.018)$ for a biallelic locus with a minor allele frequency of 0.134 (154 out of 1152 chromosomes tested).

\section{MYPT2Y v MYPT2 (primers o796/o1083)}

We derived a test for the ends of the palindrome Pl. This locus is present in two copies on the Y chromosome, where the proximal copy is situated between the amplicons b3 and $\mathrm{r} 2(D A Z 2)$ and the distal copy is situated distal to amplicon b4 and, thus, outside the $A Z F C$ interval. This locus is part of a block with $98 \%$ identity to the MYPT2 gene on chromosome 1 . The gene on the $\mathrm{Y}$ chromosome is a pseudogene that we refer to as MYPT2Y-ps. This test amplifies MYPT2Y-ps (173 bp), together with MYPT2, on chromosome 1 (168 bp), and was used to screen patients with a suspected deletion.

\section{$Y p \vee X q$ (primers 0955/o1024)}

This test is derived from the PCDHX and PCDHY genes on Yp and Xq. It controls for high levels of $46, X Y / 45, X$ mosaicism which, if present, could lead to false deletion detection by the other dose tests. This possibility was excluded for all individuals except two males of unknown fertility who do not have a partial $A Z F C$ deletion.

\section{Locus specific PCR flanking DAZ1/2}

We performed two locus specific PCR assays. We derived primers (oMJ1084/oMJ1085) from either side of the P2/P1 junction fragment situated $70 \mathrm{~kb}$ distal to the $3^{\prime}$ end of $D A Z 2$. The presence of this site specific junction fragment was tested for in all groups. Only one fertile Hg-J man who had not previously shown evidence of deletion failed to amplify this fragment, indicating that there is a low frequency of $\mathrm{Y}$ chromosomes $(<0.2 \%)$ which lack this evolutionary junction fragment. This test corresponds to sY1291. ${ }^{16}$
The junction situated proximal to DAZl is defined by a sequence block that is duplicated on Yp. There is, however, a deletion/insertion difference between the Yp and the $A Z F C$ homologue that allowed us to develop a specific PCR test for $A Z F c$ with primers oMJ1276/oMJ1277. This region is part of u3 on the published $A Z F C$ map $^{4}$ and is situated close to the $50 \mathrm{f} 2 / \mathrm{C}$ locus. ${ }^{21}$ It corresponds to sY1191 ${ }^{16}$ or sYl192.. ${ }^{4}$ To determine the frequency of deletion polymorphisms at this locus in our population, we tested 242 non-deleted men (132 Hg-P, 61 Pg- $\mathrm{Y}^{*}\{\mathrm{xD}, \mathrm{E}, \mathrm{J}, \mathrm{P}\}, 20 \mathrm{Hg}-\mathrm{J}$, and $\left.29 \mathrm{Hg}-\mathrm{DE}\right)$. No deletions were found (data not shown).

\section{PCR primer pairs}

The $5^{\prime}$ to $3^{\prime}$ sequences of the unpublished oligonucleotide primers used in this study are: 0796: ctcactacatgacattcagg; 0912: tgtatttaaaatgtgcacttcactgt; 0913: ccagtcacaaaatgccacat; 0953a: tattgagaccettgcacctg; 0955: aatttcttcacagccagacagc; o1023: gtttcttggagtttccettctgtcacc; o1024: gtttcttgcactattcattg cacagac; ol025: gaaatgccataatgtgctaacactg; o1026: aagga gagtgttaatacatacctg; ol083: gttcttcccagtatctagtacagtgc; o 1084: agaactgccaggtctgtgtc; ol085: ttgccacaaagagatagctctgg; ol130: ttaagtactactgtagacac; ol187: gttcaggcacatggcatagc; ol188: ccactcacagttttgtggtc; ol195: cttcaacctcaaactcctgg; o1207: gtttcttccactgtagaaattcacctcc; o1208: gaagtttgcatagtg gacagc; ol226: aactgagctgcactggtgac; ol227: ccccgaatgaccag cagcc; o1276: agtctgagtggctagtgcac; ol277: gaagcaaagtt cagctgtgc; ol313: gtttcttgtataatgtagaagagtagagc.

The following annealing temperatures were used: 0796/ ol083: $56^{\circ} \mathrm{C}$; $0912 / 0913$ : $54^{\circ} \mathrm{C}$; $0953 \mathrm{a} / 01023$ : $58^{\circ} \mathrm{C}$; $0955 /$ ol024: $54^{\circ} \mathrm{C}$; ol025/o1026: $58^{\circ} \mathrm{C}$; ol $084 / 01085$ : $60^{\circ} \mathrm{C}$; oll $130 /$ ol313: $54^{\circ} \mathrm{C}$; ol $187 / 01188$ : $60^{\circ} \mathrm{C}$; ol $187 / 01195$ : $58^{\circ} \mathrm{C}$; o1207/ ol208: $56^{\circ} \mathrm{C}$; ol226/ol227: $60^{\circ} \mathrm{C}$; ol276/ol277: $60^{\circ} \mathrm{C}$.

\section{Y haplotyping}

Y haplotyping was performed as previously published for the YAP, ${ }^{22}$ M9, ${ }^{23}{ }^{24}$ SRY4064, ${ }^{25}{ }^{26}$ and $92 \mathrm{R}^{25}{ }^{26}$ polymorphisms. The Tat polymorphism ${ }^{27}$ was assayed by PCR digestion with primers ol489: atgtatatagtacgtctgtagg and ol490: gtaagca taattgagaaggtgcc (annealing at $54^{\circ} \mathrm{C}$ ). The $12 \mathrm{f} 2$ assay was performed as a duplex with SRY primers 3'SRY15 and $3^{\prime}$ SRY 16 and $12 \mathrm{f} 2$ primers $12 \mathrm{f} 2 \mathrm{D}$ and $12 \mathrm{f} 2 \mathrm{~F} .{ }^{26}$ These primer pairs were used at a concentration of $300 \mathrm{nM}$ for each $S R Y$ primer and $600 \mathrm{nM}$ for each $12 \mathrm{f} 2$ primer and the annealing temperature used was $52^{\circ} \mathrm{C}$. Polymorphisms were visualised by restriction enzyme digest for M9 (HinfI), SRY4064 (BsrBI), Tat (HpyCH4IV), and 92R7 (HindIII).

All men were haplotyped for YAP, 12f2, and 92R7 polymorphisms (table 1), and individuals with partial AZF deletions were further genotyped with the Tat, M9, and SRY4064 SNPs, defining five haplogroups, E, J, K(xN3,P), N3, and $\mathrm{P}$, and one paragroup $\mathrm{Y}^{*}(\mathrm{xD}, \mathrm{E}, \mathrm{J}, \mathrm{K})$.

Table $1 \mathrm{Y}$ haplogroup distribution in the four study populations and numbers of microdeletions (complete $A Z F c$, or b2/b4, deletions) and partial AZFc deletions

\begin{tabular}{|c|c|c|c|c|c|c|c|c|c|c|c|c|}
\hline \multirow[b]{3}{*}{ Population } & \multicolumn{12}{|c|}{ Y Haplogroup } \\
\hline & \multicolumn{3}{|l|}{$\mathbf{P}$} & \multicolumn{3}{|l|}{ J } & \multicolumn{3}{|l|}{$\mathrm{DE}$} & \multicolumn{3}{|c|}{$Y^{*}(x D, E, J, P)$} \\
\hline & (micro) & $n$ & (part) & (micro) & $n$ & (part) & (micro) & n & (part) & (micro) & n & (part) \\
\hline $\begin{array}{l}\leqslant 5 \mathrm{M} / \mathrm{ml}(\mathrm{n}=263) \\
\% \text { of total }\end{array}$ & (7) & $\begin{array}{r}141 \\
54\end{array}$ & (6) & (1) & $\begin{array}{l}28 \\
11\end{array}$ & (1) & (0) & $\begin{array}{l}47 \\
18\end{array}$ & (5) & (2) & $\begin{array}{l}47 \\
18\end{array}$ & (3) \\
\hline$>5 \mathrm{M} / \mathrm{ml}(\mathrm{n}=46)$ & (0) & 23 & (1) & (0) & 4 & (1) & (0) & 10 & (1) & (0) & 9 & (0) \\
\hline$\%$ of total & (10) & 50 & 117 & (10) & 9 & & & 22 & & & 19 & \\
\hline Unknown fertility $(n=210)$ & (0) & $\begin{array}{r}121 \\
50\end{array}$ & (6) & (0) & 14 & (1) & (0) & 20 & (0) & (0) & 55 & (3) \\
\hline$\%$ of total & & 58 & & & 7 & & & 10 & & & 26 & \\
\hline Fertile/ normospermic $(n=189)$ & (0) & 93 & (0) & (0) & 21 & (0) & (0) & 25 & (1) & (0) & 50 & (5) \\
\hline$\%$ of total & & 49 & & & 11 & & & 13 & & & 26 & \\
\hline
\end{tabular}



present

13-1645

$D A Z$ and $C D Y 1$ SFVs: absent

13-1877 $D A Z$ and $C D Y 1$ SFVs:
present

13-2369

$D A Z$ and $C D Y 7$ SFVs: absent

DAZ and CDY 1 SFVs:
absent

13-560
$D A Z$ and $C D Y 1$ SFVs:
G1

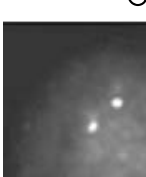

G1

G2

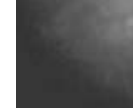

(1)

G1

1
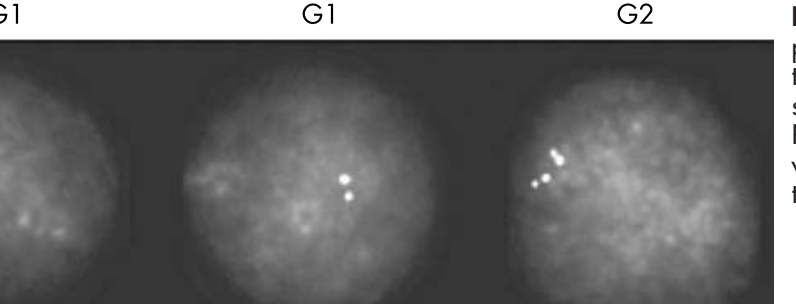

absent
Figure 3 Quantification of $D A Z$ gene pairs in interphase nuclei by FISH, using the $D A Z$ cosmid $18 \mathrm{E} 8$ as probe. Each spot corresponds to a $D A Z$ gene pair. Representative $G 1$ nuclei are shown, as well as nuclei considered to be at $G 2$ on the basis of hybridisation pattern.

\section{Statistical analysis}

We tested the significance of the observed difference in the incidence of $\mathrm{gr} / \mathrm{gr}$ deletion or SFV absence between our infertile and control populations by means of Fisher's exact test, using the program developed by $\varnothing$ Langsrud (http:// www.matforsk.no/ola/fisher.htm). Our null hypothesis was that incidence is the same in infertile and control populations. Given the exploratory nature of this study, all associations with $\mathrm{p}<0.05$ are considered as significant, and worth further study. In this study, however, we have performed 11 tests of association with infertility: four $D A Z+C D Y 1$ gr/gr deletion types, loss of four SFV sites at DAZ and CDY1, loss of a CDY1-7750 SFV (a or b) with, and without, copy loss, and presence of a gr/gr deletion. Applying the Bonferroni correction for multiple testing ( $\alpha=0.05 /$ number of tests performed), an $\alpha$ of 0.0045 is obtained. Thus, $\mathrm{p}<0.0045$ is considered the true statistical significance for this study.

\section{RESULTS}

\section{Screening for partial AZFc deletions}

In order to investigate the incidence, extent, and impact on fertility of partial $A Z F C$ deletions in a large number of fertile and infertile individuals, we characterised the apparently intact $\mathrm{Y}$ chromosomes in five groups of men in four different ways: (i) quantification of five $A Z F C$ loci, including $D A Z$ and CDYl, using quantitative PCR and FISH; (ii) detection of nucleotides (SFVs) that discriminate between members of the $D A Z$ and $C D Y 1$ gene families; (iii) the specific detection of unique fragments flanking the $D A Z 1 / 2$ gene pair at the u3 segment (proximal) and the $\mathrm{P} 2 / \mathrm{Pl}$ palindrome junction (distal), corresponding, respectively, to sY1191/sY1192 and sY1291 used in previous studies ${ }^{16}{ }^{28}$; and (iv) haplotyping with MSY binary polymorphisms. Some of these results, and a summary of the $\mathrm{Y}$ chromosome variants defined in this study, are presented in figs $1-3$.

\section{Most partial AZFc deletions of $D A Z$ or $C D Y 1 \mathrm{are} \mathrm{gr} / \mathrm{gr}$ deletions}

This combination of tests was initially used to screen 487 men. All 487 men were screened with three quantitative tests: DAZ v DAZL, CDY1-cds $v C D Y 2$, and Yp $v$ Xq. This latter test controls for cases of $46, \mathrm{XY} / 45, \mathrm{X}$ mosaicism. Some 18 men showed copy loss at both $D A Z$ and $C D Y 1$, but not Yp. These men all showed SFV loss at both DAZ (sY587-[18]) and 
CDY1-7750 and were deleted for either one of the unique markers flanking the DAZ1/2 locus. We conclude that these 18 men carry partial $A Z F C$ deletions of the $Y$ chromosome that correspond to the gr/gr deletions recently described. ${ }^{16}$

The original definition of the gr/gr deletion did not predict the deletion of the $\mathrm{u} 3$ segment. ${ }^{17}$ However a more recent study has shown that the Y chromosome of haplogroup HgN3 probably carries a gr/gr deletion..$^{28}$ The deletion of $\mathrm{u} 3$ was explained in this case by invoking the existence of an inversion around $D A Z 1 / 2$, mediated by recombination between elements b2 and b3. Our results confirm this finding and, moreover, show that $\mathrm{u} 3$ deletion is not limited to $\mathrm{Hg}-\mathrm{N} 3$ but is found on other types of Y chromosome (fig 2). We conclude that deletion of either $\mathrm{u} 3$ or the $\mathrm{P} 2 / \mathrm{Pl}$ junction, but not both, is diagnostic of gr/gr deletion.

Only three men who did not show copy loss for DAZ or CDYI showed SFV loss at both these loci. These men were, however, deleted for the u3 locus specific marker indicating that their Y chromosome carries a gr/gr deletion, but that the $D A Z$ and CDYI copy number has been restored by a subsequent b2/b4 duplication. ${ }^{16}$ We did not find any cases with SFV loss at sY587 in DAZ and CDYI that were not also deleted for one of the unique sites, $\mathrm{u} 3$ or $\mathrm{P} 2 / \mathrm{Pl}$, that flank $D A Z 1 / 2$, suggesting that in most cases either of these approaches can be used to detect gr/gr deletions. Indeed, the loss of the DAZ3/4 variant at sY587 is diagnostic of gr/gr deletion, while the loss of the DAZl/2 variant was found in only three undeleted men. Loss of the CDYI SFV is a much less reliable indicator of deletion, since, of the 49 cases detected, only 22 have a partial $A Z F C$ deletion. Copy number status was verified at CDY1-7750 using a further quantitative test, CDY1-9825 v CDY2, and the results obtained at these two loci are in complete accord. This effectively excludes the possibility that small deletions, specific to the 5' end of CDYl, are the cause of SFV absence at this site.

Two exceptional individuals showed deletions that affect either $D A Z$ or $C D Y 1$, but not both: the normospermic man, 13$2968,\left(26 \times 10^{6} \mathrm{spz} / \mathrm{ml}\right)$ is deleted for CDY1b only, while the fertile control, $\mathrm{O} / 03$, is deleted for the $D A Z 1 / 2$ gene pair only. It is likely that $\mathrm{O} / 03$ is a second case of the $\mathrm{bl} / \mathrm{b} 3$ deletion reported recently, ${ }^{16}$ but confirmation of this will require the mapping of his proximal boundary. The deletion carried by 13-2968 has not been previously reported, and shows that two copies of $C D Y 1$ are not required for normospermia.

Our results show that the vast majority of partial $A Z F C$ deletions that result in the loss of some copies of $D A Z$ and CDY1 are gr/gr deletions, mediated by unequal crossing over between two large $(\sim 540 \mathrm{~kb})$ directly repeated gr amplicons (fig 2). We also show that our combination of SFV tests and locus specific tests provides a stringent method for their detection. We therefore screened a further 212 individuals with SFV and locus specific tests only. Quantitative tests were performed in gr/gr deletion cases, as a means of detecting the $\mathrm{b} 2 / \mathrm{b} 4$ duplication. In this group we found a further $11 \mathrm{gr} / \mathrm{gr}$ deletions, one of which had a b2/b4 duplication.

All men in whom we detected a partial $A Z F c$ deletion were tested with a further quantitative test: MYPT2Y $v$ MYPT2 situated at the end of palindrome P1. Copy loss at MYPT2Y was observed in men with a gr/gr deletion who are deleted for the P2/P1 junction, but not in cases of $\mathrm{u} 3$ deletion. Indeed, in the three men predicted to have a b2/b4 duplication, whose deletions must have arisen on a b2/b3 inverted $\mathrm{Y}$ chromosome, since they include $\mathrm{u} 3$ and not the P2/P1 junction, we saw increased copy number of the MYPT2Y-ps locus (shown for 13-560 and 13-230; fig 1B). The proximal copy of MYPT2Yps would not be deleted from a b2/b3 inverted Y chromosome, and would therefore be duplicated by a b2/b4 duplication, to give three copies instead of two. This provides further evidence for the existence of the $\mathrm{b} 2 / \mathrm{b} 3$ mediated inversion polymorphism ${ }^{28}$ and b2/b4 duplications. ${ }^{16}$

Our cumulative results are summarised in fig 2 and tables 1 and 2. Overall we detected 32 gr/gr deletions, four of which carry b2/b4 duplications. Based on SFV loss and Y haplogroup, we are able to discern 17 independent gr/gr deletions.

\section{Quantification of DAZ gene pairs by FISH}

FISH analysis with the DAZ cosmid 18E8 was performed on four infertile individuals without SFV loss at either SY587 or CDY1-7750 and on one fertile and six infertile individuals ( ${ }^{* *}$ in fig 1B) with SFV absence at both these loci. This confirmed our PCR based analyses. Representative results are shown in fig 3.

One infertile man without SFV loss, 13-1877, showed 62\% of nuclei with three or more signals, and only $35 \%$ of nuclei with two signals. We conclude that 13-1877 has three pairs of $D A Z$ genes, and this was corroborated by PCR based dose tests (data not shown). A similar $D A Z$ gene pair duplication has recently been described in a fertile sperm donor. ${ }^{29}$ This duplication is most likely the result of the event reciprocal to the gr/gr deletion.

\section{Loss of $D A Z 1 / 2$ or $D A Z 3 / 4$}

Using sets of SFVs that discriminate between each $D A Z$ gene, other studies have concluded that partial $A Z F C$ deletions can result in the loss of one, two, or three $D A Z$ genes. ${ }^{14}{ }^{15}$ Our combined quantification and SFV analysis of the $D A Z$ gene family in 487 men allowed us to address this question.

Out of 487 men, we identified 19 individuals with reduced $D A Z$ copy number, who all lack the SFV at sY587. Since the SFV at sY587 differentiates DAZ1 and DAZ2 from DAZ3 and $D A Z 4$, this shows that the vast majority of partial $A Z F C$ deletions remove either the $D A Z 1 / 2$ gene pair or the $D A Z 3 / 4$ gene pair, but not combinations of two $D A Z$ genes from each gene pair. Since there are normally four $D A Z$ genes and two DAZL genes, DAZ:DAZL ratios of $66 \%: 33 \%$, $50 \%: 50 \%$, or $33 \%: 66 \%$ are expected, respectively, in cases where no, two, or three $D A Z$ genes have been deleted. Since we never observed the $33 \%: 66 \%$ ratio, we conclude that deletions of three $D A Z$ genes are extremely rare. Although there is no obvious mechanism by which single $D A Z$ gene deletions could arise, we cannot formally exclude their existence, since the expected difference in DAZ:DAZL dose ratios, $60 \%: 40 \%$ as compared to $66 \%: 33 \%$, is too slight to measure reliably.

Inversion polymorphism in the $D A Z 3 / 4$ palindrome $P 1$ In the $\mathrm{Y}$ chromosome reference sequence, ${ }^{2030}$ CDYlb lies outside the region that is predicted to be deleted by gr/gr recombination. We nevertheless detected 14 partial $A Z F C$ deletions that result in the loss of $C D Y I b$, but that otherwise have all the characteristics of "classic" gr/gr deletions. These deletions involving CDYIb can, therefore, be explained either by invoking a second inversion polymorphism of the Pl palindrome, or the gene conversion of CDYIa by CDYIb prior to deletion. This latter possibility is very unlikely, as $C D Y 1 b$ deletions represent $14 / 32$, or $48 \%$, of the gr/gr deletions, and the observed frequency of this gene conversion event is $<1 \%$. It therefore seems likely that there is a further inversion polymorphism that may be mediated by crossing over between the homologous inverted segments b3 and b4. This suggests that there are at least four possible orders for sequences in this interval, and we find evidence for all four possibilities in the current study (fig 4). In light of these inversion variants, which place amplicon g3 within a gr amplicon (fig 4), we suggest that the original definition of gr/gr deletion ${ }^{16}$ should be extended to include any deletion that has arisen through unequal crossing over within $\mathrm{g}$ or $\mathrm{r}$ 


\begin{tabular}{|c|c|c|c|c|c|c|c|c|}
\hline \multirow[b]{4}{*}{ SFV absent } & \multicolumn{8}{|c|}{ Population } \\
\hline & \multirow{2}{*}{\multicolumn{2}{|c|}{$\begin{array}{l}\leqslant 5 \mathrm{M} / \mathrm{ml} \\
\mathrm{n}=254\end{array}$}} & \multirow{2}{*}{\multicolumn{2}{|c|}{$\begin{array}{l}>5 \mathrm{M} / \mathrm{ml} \\
\mathrm{n}=46\end{array}$}} & \multirow{2}{*}{\multicolumn{2}{|c|}{$\begin{array}{l}\text { Unknown } \\
\mathrm{n}=210\end{array}$}} & \multirow{2}{*}{\multicolumn{2}{|c|}{$\begin{array}{l}\text { Fertile/normo } \\
n=189\end{array}$}} \\
\hline & & & & & & & & \\
\hline & $\%$ & (n) & $\%$ & (n) & $\%$ & (n) & $\%$ & (n) \\
\hline$D A Z 1 / 2$ & 2.4 & (6) & 4.3 & (2) & 1.9 & (4) & 3.2 & (6) \\
\hline$D A Z 3 / 4$ & 3.5 & (9) & 2.2 & (1) & 2.8 & (6) & 1.1 & (2) \\
\hline CDYla & 9.4 & (24) & 6.5 & (3) & 4.3 & (9) & 2.7 & (5) \\
\hline CDYIb & 3.1 & (8) & 4.3 & (2) & 2.4 & (5) & 2.1 & (4) \\
\hline DAZ1/2+CDYla & 1.6 & (4) & 4.3 & (2) & 1.4 & (3) & 0.5 & (1) \\
\hline$D A Z 1 / 2+C D Y 1 b$ & 0.8 & (2) & 0 & (0) & 0.5 & (1) & 0.5 & (1) \\
\hline$D A Z 3 / 4+C D Y 1 a$ & 2.4 & (6) & 0 & (0) & 1.0 & (2) & 0 & (0) \\
\hline$D A Z 3 / 4+C D Y 1 b$ & 1.2 & (3) & 2.2 & (1) & 1.9 & (4) & 1.1 & (2) \\
\hline
\end{tabular}

\begin{tabular}{|c|c|c|c|c|c|c|c|c|}
\hline \multirow[b]{4}{*}{ SFV absent } & \multicolumn{8}{|c|}{ Population } \\
\hline & \multirow{2}{*}{\multicolumn{2}{|c|}{$\begin{array}{l}\leqslant 5 \mathrm{M} / \mathrm{ml} \\
\mathrm{n}=254\end{array}$}} & \multirow{2}{*}{\multicolumn{2}{|c|}{$\begin{array}{l}>5 \mathrm{M} / \mathrm{ml} \\
\mathrm{n}=46\end{array}$}} & \multirow{2}{*}{\multicolumn{2}{|c|}{$\begin{array}{l}\text { Unknown } \\
n=210\end{array}$}} & \multirow{2}{*}{\multicolumn{2}{|c|}{$\begin{array}{l}\text { Fertile/normo } \\
n=189\end{array}$}} \\
\hline & & & & & & & & \\
\hline & $\%$ & (n) & $\%$ & (n) & $\%$ & (n) & $\%$ & (n) \\
\hline DAZI/2 & 2.4 & (6) & 4.3 & (2) & 1.9 & (4) & 1.6 & (3) \\
\hline$D A Z 3 / 4$ & 3.5 & (9) & 2.2 & (1) & 2.9 & (6) & 1.1 & (2) \\
\hline CDYla & 3.9 & (10) & 4.3 & (2) & 2.4 & (5) & 0.5 & (1) \\
\hline CDYIb & 2.0 & (5) & 2.2 & (1) & 2.4 & (5) & 2.1 & (4) \\
\hline$D A Z 1 / 2+C D Y 1 a$ & 1.6 & (4) & 4.3 & (2) & 1.4 & (3) & 0.5 & (1) \\
\hline$D A Z 1 / 2+C D Y 1 b$ & 0.8 & (2) & 0 & (0) & 0.5 & (1) & 0.5 & (1) \\
\hline DAZ3/4+CDYla & 2.4 & (6) & 0 & (0) & 1.0 & (2) & 0 & (0) \\
\hline DAZ3/4+CDY1b & 1.2 & (3) & 2.2 & (1) & 1.9 & (4) & 1.1 & (2) \\
\hline
\end{tabular}

amplicons. The fact that even in only 32 men with a gr/gr deletion each haplogroup defined contains at least two inversion variants suggests that these inversions are relatively frequent events.

\section{Genetic exchange within the non-recombining $Y$ chromosome}

A previous study concluded that SFV absence was the result of gene conversion between the arms of the large palindromes that make up most of the $A Z F c$ interval, but internal $A Z F c$ deletions in the fertile population were not considered as a possible alternative explanation, and no quantification was performed at the loci studied. ${ }^{31}$ Here, we establish that the majority of cases of SFV absence at CDYI-7750 are not associated with gr/gr deletion or copy loss. We therefore further investigated this question for two SFVs at the CDYI locus, in our population of individuals known to carry two copies of CDYI. The SFVs used were CDY1-7750 and CDYI-84, from the 5' UTR of $C D Y 1$. This latter polymorphism has been published independently. ${ }^{31}$

A comprehensive phylogeny of human Y chromosomes, based on the genotyping of MSY binary polymorphisms, is now available. ${ }^{25}$ The genotyping of our study population allowed us to assign individuals to specific branches of the phylogeny and determine the relative position of SFV loss or acquisition.

The results for 465 undeleted men are summarised in fig 5 . Our analysis shows that the CDYI SFVs used are present on

\begin{tabular}{|c|c|c|c|c|c|c|c|c|}
\hline \multirow[b]{4}{*}{ SFV absent } & \multicolumn{8}{|c|}{ Population } \\
\hline & \multirow{2}{*}{\multicolumn{2}{|c|}{$\begin{array}{l}\leqslant 5 \mathrm{M} / \mathrm{ml} \\
\mathrm{n}=254\end{array}$}} & \multirow{2}{*}{\multicolumn{2}{|c|}{$\begin{array}{l}>5 \mathrm{M} / \mathrm{ml} \\
\mathrm{n}=46\end{array}$}} & \multirow{2}{*}{\multicolumn{2}{|c|}{$\begin{array}{l}\text { Unknown } \\
n=210\end{array}$}} & \multirow{2}{*}{\multicolumn{2}{|c|}{$\begin{array}{l}\text { Fertile/normo } \\
n=189\end{array}$}} \\
\hline & & & & & & & & \\
\hline & $\%$ & (n) & $\%$ & (n) & $\%$ & (n) & $\%$ & (n) \\
\hline$D A Z 1 / 2$ & 0 & (0) & 0 & (0) & 0 & (0) & 1.6 & (3) \\
\hline$D A Z 3 / 4$ & 0 & (0) & 0 & (0) & 0 & (0) & 0 & (0) \\
\hline CDYla & 6.7 & (14) & 2.2 & (1) & 1.9 & (4) & 2.1 & (4) \\
\hline CDYIb & 1.4 & (3) & 2.2 & (1) & 0 & (0) & 0 & (0) \\
\hline DAZ1/2+CDYla & 0 & (0) & 0 & (0) & 0 & (0) & 0 & (0) \\
\hline$D A Z 1 / 2+C D Y 1 b$ & 0 & (0) & 0 & (0) & 0 & (0) & 0 & (0) \\
\hline DAZ3/4+CDYla & 0 & (0) & 0 & (0) & 0 & (0) & 0 & (0) \\
\hline$D A Z 3 / 4+C D Y 1 b$ & 0 & (0) & 0 & (0) & 0 & (0) & 0 & (0) \\
\hline
\end{tabular}

normo, normospermic. 


Inversion

all four $\mathrm{Y}$ chromosomes defined, demonstrating that the presence of these two CDYI SFVs is the ancestral state of all the derived Y chromosomes. Furthermore, SFV loss is not limited to the non-derived Y chromosomes, but is found in all four groups. We conclude that the majority of SFV loss at the CDY1 loci tested does not result from deletion, but that, as previously proposed, ${ }^{31}$ it is frequently a consequence of intrapalindrome gene conversion.

It is clear from our data that for an SFV to be a useful indicator of partial deletion, the incidence of its absence from intact Y chromosomes must be estimated for the Y haplotypes that compose the study group. This has not been done in other studies. ${ }^{14} 15$

\section{$D A Z$ and $C D Y 1$ copy number on the $\mathrm{gr} / \mathrm{gr}$ deleted $\mathrm{Hg}$ - N3 Y chromosome}

It has been proposed that $\mathrm{b} 2 / \mathrm{b} 4$ duplication may be a way in which full spermatogenic activity can be restored to an individual carrying a gr/gr deleted Y chromosome. ${ }^{16}$ If gr/gr deletions have an effect on spermatogenesis by reducing gene

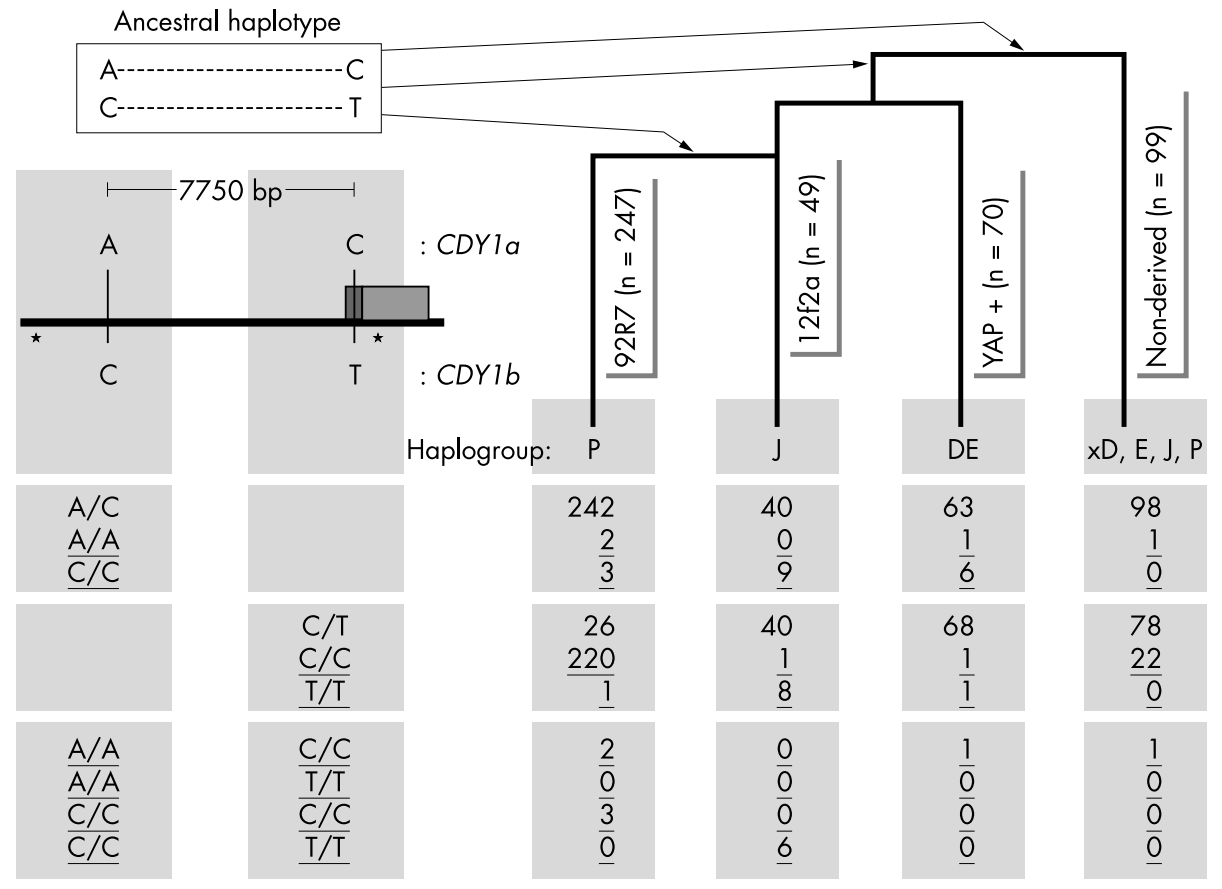

Figure 5 SFV loss on intact $Y$ chromosomes by intrachromosomal genetic exchange at two sites $5^{\prime}$ to $C D Y 1$ in the AZFc interval. The number of individuals observed for each genotype at the SFV site is shown for each Y haplogroup determined. Genotypes with SFV absence are underlined. Asterisks indicate the positions of the two dose tests used. Also shown are the numbers of individuals who have the SFV at neither site. The presence of the SFV is found on each of the four $Y$ chromosomes defined, showing that the SFV is ancestral and that its absence from a $Y$ chromosome carrying two copies of $C D Y 1$ must result from genetic exchange between the CDY1 genes. 
dosage, then a strong selection for these re-duplicated gr/gr deleted chromosomes would be expected, and consequently gr/gr deleted Y chromosomes present at a high percentage in a population would be the duplicated, rescued form. Two examples of gr/gr deleted Y chromosomes that have attained a high prevalence in certain populations have so far been described: the Hg-D2b Y chromosome present in $20-30 \%$ of Japanese men, ${ }^{1632}$ and the Hg-N3 Y chromosome present in $50 \%$ of Finnish men. ${ }^{21} 2728$ The gr/gr deletion on the Hg-D2b $\mathrm{Y}$ chromosome is associated with a sperm count of $>40 \times 10^{6} \mathrm{spz} / \mathrm{ml}$ in $66 \%$ of fertile carriers. ${ }^{33}$ It has been shown by FISH that the D2b gr/gr deleted Y chromosome does not carry a b2/b4 duplication. ${ }^{16}$ This information is, however, not yet known for the Hg-N3 Y chromosome.

Using the Tat bi-allelic marker, we identified three control men and one infertile man with an Hg-N3 Y chromosome, all of whom carry the same gr/gr deletion, type $4 \mathrm{~b}$, deleted for $C D Y 1 b, D A Z 3 / 4$, and u3. Our results confirm that the $\mathrm{Y}$ chromosome on which the Hg-N3 deletion arose carried a b2/b3 inversion around $D A Z 1 / 2,{ }^{28}$ but show in addition that it carried a second inversion of the Pl palindrome around $D A Z 3 / 4$. Dose tests revealed that only one fertile $\mathrm{Hg}-\mathrm{N} 3$ man carries a b2/b4 duplication, and thus has four copies of $D A Z$ and two copies of $C D Y 1$, while three others have only two copies of DAZ and one copy of CDY1. There would therefore appear to have been no strong selection for the $b 2 / b 4$ duplication among men with either Hg-D2b or Hg-N3 Y chromosomes. Indeed, we and others ${ }^{16}$ have found that b2/b4 duplications are generally rare among the gr/gr deleted chromosomes, indicating that the majority of gr/gr deletions have little effect on male fertility.

\section{DAZ and CDY 1 SFVs define four deletion types}

Partial $A Z F C$ deletions of both $D A Z$ and $C D Y 1$ were not found with significantly different frequencies in infertile and control populations: 18 infertile men $(6 \%)$ and 14 control men $(3.5 \%)(p=0.085)$ had such deletions. We therefore investigated the possibility that certain types of gr/gr deletion are associated with male infertility. The incidence of SFV loss without deletion at DAZ (sY587) or CDY1-7750 loci was low (table 2C), indicating that these SFVs can be used to define deleted loci with a low error rate. On the basis of the $D A Z$ and CDYI SFVs retained, we were able to define four gr/gr deletion types (fig 2 and table 2B).

Similar frequencies of gr/gr deletions of $C D Y 1 b$ with either DAZ1/2 (0.7\% v $0.5 \%)$ or DAZ3/4 (1.3\% v $1.5 \%)$ were observed for infertile versus control populations. Deletion of CDYla with $D A Z 1 / 2$ is slightly more frequent in infertile populations $(2.3 \%$ v $1.0 \% ; \mathrm{p}=0.14)$. However, a statistically significant, but weak, association with infertility was observed only with the type $4 \mathrm{gr} / \mathrm{gr}$ deletion characterised by DAZ3/4 and CDYla SFV loss: $6 / 254$ infertile men with $<5 \times 10^{6} \mathrm{spz} / \mathrm{ml}$ and 2/399 control men $(p=0.042)$ had this deletion. No fertile men carried this deletion (0/189). We did, however, find this deletion in a man with agenesis of the vas deferens who carries two mutations of the CFTR gene (13-4255; fig 2), further weakening this association between type $4 \mathrm{gr} / \mathrm{gr}$ deletion and infertility. Collectively, the incidence of gr/gr deletion of CDYla shows a weak association with infertility: $12 / 300$ infertile men $v 6 / 399$ control men $(p=0.035)$ had this deletion.

\section{Loss of the CDY1-7750 SFV is associated with infertility}

Comparing our infertile and control populations, we found similar frequencies of SFV absence for DAZ1/2, DAZ3/4, or CDYlb (distal), with and without deletion (table 2A). There was, however, a significantly higher frequency in the infertile compared to the control populations for the absence of the CDYla SFV (proximal) at CDY1-7750 (27/300 v 14/399; $\mathrm{p}=0.002)$. This result is significant even when the number of tests is taken into account (significance: $p<0.0045$; see Methods). This indicates that the absence of this SFV is associated with infertility. This increase is found for all four haplogroups defined (table $3 \mathrm{~A}$ ) and is at the limit of statistical significance in the largest, Hg-P (10/157 v 5/214; $\mathrm{p}=0.047)$.

Table 2C shows the incidence of SFV absence without deletion. In men in whom there is no evidence of a partial $A Z F c$ deletion, absence of a CDY1-7750 variant (a or b) is significantly more frequent in the infertile than the control population, even when multiple testing is taken into account $(19 / 282 \vee 8 / 383 ; p=0.0026)$. Absence of each variant at CDY1-7750 is also significantly higher in infertile men compared to control men: 15/282 v 8/383 for CDYIa $(\mathrm{p}=0.02)$ and $4 / 282 v 0 / 383$ for CDYIb $(\mathrm{p}=0.03)$. The higher incidence of CDY1-7750 absence is seen in all three derived haplogroups (table 3B), suggesting that it is not an artefact of population stratification. This indicates that loss of a segment of the $A Z F C$ interval defined by CDY1-7750 has a deleterious effect on male fertility. The mechanism for this loss is not clear and will require further study. Since SFV loss is not associated with copy loss in these cases, a deletion of a gr/gr duplicated chromosome, such as we describe in patient 13 1877 , is one possibility. In this case, the absence of a locus flanking CDY1-7750 could underlie the infertility. If, on the other hand, gene conversion were responsible, the SFV at CDY1-7750 would be required for full male fertility.

\section{DISCUSSION}

Most gr/gr deletions have little effect on male fertility Here, we show that the majority of partial $A Z F C$ deletions that affect copies of $C D Y 1$ or $D A Z$ are probably mediated by gr/gr amplicon recombination. Based on the $D A Z$ and $C D Y 1$ genes deleted, we sub-divided the gr/gr deletions found into four types. Deletions of CDYla show a weak association with infertility, suggesting that some may cause infertility. On the other hand, deletions of $C D Y 1 b$, representing $48 \%$ of the total

\begin{tabular}{|c|c|c|c|c|c|c|c|c|c|c|c|c|}
\hline \multirow[b]{4}{*}{ Population } & \multicolumn{12}{|c|}{ Y Haplogroup } \\
\hline & \multicolumn{3}{|l|}{$\bar{P}$} & \multicolumn{3}{|l|}{$\mathrm{J}$} & \multicolumn{3}{|l|}{ DE } & \multicolumn{3}{|c|}{$Y^{*}(x D, E, J, P)$} \\
\hline & \multicolumn{3}{|c|}{ CDY1-7750 } & \multicolumn{3}{|c|}{ CDY1-7750 } & \multicolumn{3}{|c|}{ CDYI-7750 } & \multicolumn{3}{|c|}{ CDYI-7750 } \\
\hline & $\overline{\text { (a) }}$ & Total & (b) & (a) & Total & (b) & $\overline{\text { (a) }}$ & Total & (b) & $\overline{\text { (a) }}$ & Total & (b) \\
\hline$\leqslant 5 \mathrm{M} / \mathrm{ml}$ & (9) & 134 & (2) & (7) & 28 & (1) & (6) & 47 & (3) & (2) & 47 & (2) \\
\hline$>5 \mathrm{M} / \mathrm{ml}$ & (1) & 23 & (0) & (1) & 4 & (0) & (1) & 10 & (2) & (0) & 9 & (0) \\
\hline Unknown fertility & (5) & 121 & (2) & (3) & 14 & (1) & (0) & 20 & (0) & (1) & 55 & (2) \\
\hline Fertile/normospermic & (0) & 93 & (0) & (3) & 21 & (0) & (1) & 25 & (1) & (1) & 50 & (3) \\
\hline Total & (15) & 371 & (4) & (14) & 67 & (2) & (8) & 102 & (6) & (4) & 161 & (7) \\
\hline
\end{tabular}




\begin{tabular}{|c|c|c|c|c|c|c|c|c|c|c|c|c|}
\hline \multirow[b]{4}{*}{ Population } & \multicolumn{12}{|c|}{ Y Haplogroup } \\
\hline & \multicolumn{3}{|l|}{$\overline{\mathbf{P}}$} & \multicolumn{3}{|l|}{ J } & \multicolumn{3}{|l|}{ DE } & \multicolumn{3}{|c|}{$Y^{*}(x D, E, J, P)$} \\
\hline & \multicolumn{3}{|c|}{ CDY1-7750 } & \multicolumn{3}{|c|}{ CDYI-7750 } & \multicolumn{3}{|c|}{ CDY1-7750 } & \multicolumn{3}{|c|}{ CDY1-7750 } \\
\hline & (a) & Total & (b) & (a) & Total & (b) & (a) & Total & (b) & (a) & Total & (b) \\
\hline $\begin{array}{l}\leqslant 5 \mathrm{M} / \mathrm{ml} \\
>5 \mathrm{M} / \mathrm{ml} \\
\text { Unknown fertility } \\
\text { Fertile/normospermic } \\
\text { Total }\end{array}$ & $\begin{array}{l}\text { (3) } \\
\text { (0) } \\
(1) \\
\text { (0) } \\
\text { (4) }\end{array}$ & $\begin{array}{r}128 \\
22 \\
115 \\
93 \\
358\end{array}$ & $\begin{array}{l}\text { (2) } \\
(0) \\
(0) \\
(0) \\
(2)\end{array}$ & $\begin{array}{r}(7) \\
(0) \\
(3) \\
(3) \\
(13)\end{array}$ & $\begin{array}{r}27 \\
3 \\
13 \\
21 \\
64\end{array}$ & $\begin{array}{l}\text { (0) } \\
(0) \\
(0) \\
(0) \\
0)\end{array}$ & $\begin{array}{l}\text { (4) } \\
\text { (1) } \\
(0) \\
(1) \\
\text { (6) }\end{array}$ & $\begin{array}{r}42 \\
9 \\
20 \\
24 \\
95\end{array}$ & $\begin{array}{l}\text { (0) } \\
(1) \\
(0) \\
(0) \\
(1)\end{array}$ & $\begin{array}{l}10) \\
(0) \\
10) \\
10) \\
10)\end{array}$ & $\begin{array}{r}41 \\
9 \\
52 \\
45 \\
148\end{array}$ & $\begin{array}{l}\text { (1) } \\
(0) \\
(0) \\
(0) \\
(1)\end{array}$ \\
\hline
\end{tabular}

number of gr/gr deletions, are present in $2 \%$ of both infertile and control populations, suggesting that they represent variants of the Y chromosome with little effect on fertility. Our results do not exclude the possibility that certain gr/gr deletions, occurring on particular Y chromosomes, could be the cause of male infertility, but they do strongly suggest that most gr/gr deletions do not have a significant effect on male fertility. Our study therefore challenges the conclusion of a recent study, ${ }^{16}$ that the majority of gr/gr deletions affect male fertility through a reduction in sperm production. It remains possible that all gr/gr deletions reduce sperm numbers. This question could best be addressed by comparing sperm counts in groups of fertile men carrying the same gr/gr deletion with and without b2/b4 duplications.

\section{$\mathrm{gr} / \mathrm{gr}$ recombination is not evenly distributed in the $\mathrm{gr}$ amplicon}

It was originally assumed that the gr/gr unequal cross over frequency must be comparable to that of the b2/b4 event that generates the complete $A Z F c$ deletion because, at $\sim 540 \mathrm{~kb}$, the gr amplicon is more than twice the length of the b2 or b4 amplicon. ${ }^{16}$ On this basis, it was estimated that $\mathrm{gr} / \mathrm{gr}$ deletions must have a negative effect on infertility, otherwise they would be present on $>40 \%$ of contemporary Y chromosomes. The fact that in 487 men we did not observe any $D A Z$ gene copy loss without sY587 SFV loss shows that most gr/gr deletions do not occur through unequal cross over in the $135 \mathrm{~kb}$ segment situated between the two sY587 sites of each $D A Z$ gene pair. In contrast, the type $1 b, 2 c, 3 d$, and $4 a$ deletions (fig 2), representing 15 of the $32 \mathrm{gr} / \mathrm{gr}$ deletions (eight of 17 independent events), must have their proximal breakpoint in the $70 \mathrm{~kb}$ situated between sY587 in the $3^{\prime}$ end of DAZ2 and the distal end of the P2 palindrome, identifying this region as a relative hotspot of unequal crossing over. Our results show that the gr/gr deletion frequency is independent of the length of homology. Thus, the incidence of $\mathrm{gr} / \mathrm{gr}$ deletions in the general population provides no support for their negative effect on fertility.

\section{gr/gr deletions and normospermia}

In the study that found a significant association between gr/ gr deletions and spermatogenic failure (9/246 infertile men and $0 / 148$ normospermic men; $p<0.014$, Fisher's exact test, one-sided), the men in the normospermic population were characterised by a total sperm count of $>40 \times 10^{6}$. In our study, we identified two infertile men with $>40 \times 10^{6}$ spermatozoa in their ejaculate who carry distinct gr/gr deletions (13-1485 and 13-3446; fig 2). These two men were part of a group of 24 men, from infertile couples, who had sperm counts of $>20 \times 10^{6}$ per millilitre. This high incidence of gr/gr deletion (8.3\%) in a group characterised by a high sperm count indicates that most gr/gr deletions have little or no effect on sperm production.
In the published association study, gr/gr deletions were initially identified by a negative result for the P2/P1 junction marker, sY1291. ${ }^{16}$ This strategy was chosen, prior to the discovery of the b2/b3 inversion polymorphism, ${ }^{28}$ on the basis of an earlier theoretical description of gr/gr deletions. ${ }^{17}$ When a gr/gr deletion occurs on a b2/b3-inverted chromosome, however, $\mathrm{u} 3$ is deleted instead of the $\mathrm{P} 2 / \mathrm{Pl}$ junction. Although a u3 marker was used in that study, ${ }^{16}$ all $27 \mathrm{gr} / \mathrm{gr}$ deletions identified were negative for the P2/P1 marker, and none for the $\mathrm{u} 3$ marker, and it is unclear whether u3 was screened for in all men or only in men negative for the P2/P1 junction. This same study did not identify the u3-gr/gr deletion in two $\mathrm{Hg}-\mathrm{N} 3$ individuals, demonstrating that the authors' screening strategy did not detect all gr/gr deletions. In contrast, we found nine u3-deleted chromosomes out of 32 gr/gr deletions. Thus, the study showing a link between gr/gr deletion and reduced sperm production may not include $25 \%$ of the total number of gr/gr deletions present in the groups of men studied. The proposed link between gr/gr deletion and reduced sperm count should, therefore, be disregarded until the u3-gr/gr deletions, which remove more genes than the Pl/ $\mathrm{P} 2$-gr/gr deletions, ${ }^{28}$ are taken into account.

\section{AZFc genes and human fertility}

It has been proposed that partial $A Z F C$ deletions may affect male fertility by reducing the dose of certain $A Z F C$ genes. ${ }^{16}$ In consequence, any gr/gr deletion should reduce fertility and should be subject to negative reproductive selection. The results of our study reveal weaknesses in the main lines of evidence advanced in support of this model, suggesting that gene copy loss through gr/gr deletion often has little effect on human fertility.

We suggest, therefore, that an alternative model in which most gr/gr deletions are neutral, and the rate of gr/gr deletion is much lower than that of complete $A Z F C$ deletion, should also be considered. The effects of gr/gr deletions would be determined by the presence of sequence dependent loss-offunction differences between $A Z F c$ genes, and would only be seen when the functional copy is deleted and the mutated copy retained. No effect of gr/gr deletion would be seen on $\mathrm{Y}$ chromosomes with identical gene copies, or if the mutated copy was deleted. The effect of $\mathrm{gr} / \mathrm{gr}$ deletion would, therefore, be expected to vary on Y chromosomes of different haplogroups.

The relatively strong association observed in our study between infertility and SFV loss at CDY1-7750 without a reduction in copy number, represents the first evidence that, in conjunction with partial AZFc deletion or gene conversion, sequence dependent loss-of-function differences between $A Z F c$ gene copies may frequently be the basis for spermatogenic failure. The further study of these variants could lead to the identification of the $A Z F C$ genes that are necessary for efficient spermatogenesis in man. 


\section{ACKNOWLEDGEMENTS}

We are grateful to all the individuals who agreed to participate in this study. We also owe thanks to Professors Marc Gamerre and Agnes Noizet of the Centre de Procréation Médicalement Assistée in Marseilles for their help in obtaining patient material and clinical information, to Professor Philippe De Micco of the Etablissement Français du Sang Alpes-Méditerranée for his help in obtaining anonymous control samples, and to Howard Kahn for the CEPH samples. We thank David Page and Laura Brown for sending cosmid 18E8. We thank Alice Sansonetti for technical assistance, and Margaret Mitchell for proof reading the manuscript.

\section{ELECTRONIC-DATABASE INFORMATION}

The program developed by $\varnothing$ Langsrud is available at http:// www.matforsk.no/ola/fisher.htm (accessed 19 August 2004).

\section{Authors' affiliations \\ N Machev, N Saut, G Longepied, A Navarro, N Levy, J Belougne,} E Clemente, C Durand, A Ducourneau, M-G Mattei, M J Mitchell, Inserm U.491, Faculté de médecine, 13385 Marseille, France

P Terriou, Institut de Médecine de la Reproduction, 13008 Marseille, France

M Guichaoua, C Metzler-Guillemain, Laboratoire de spermiologie, Hôpital de la Conception, 13385 Marseille, France

P Collignon, A-M Frances, Service de Génétique, Centre Hospitalier de Toulon, 83056 Toulon, France

J Chiaroni, Etablissement Français du Sang Alpes-Mediterranee, 13005 Marseille, France

C Chevillard, Inserm U.399, Faculté de médecine, 13385 Marseille, France

N Pech, E.A. Biodiversité, Université de Provence, 13331 Marseille, France

K McElreavey, Reproduction, Fertility and Populations, Institut Pasteur, 75015 Paris, France

This work was supported by funding from the French national medical research body, Inserm. NS was supported by a studentship from the Ministère de l'Education Nationale, de l'Enseignement Supérieur et de la Recherche (MENESR) and a grant from the Fondation Médicale pour la Recherche.

Conflict of interest: none declared.

The authors wish it to be known that, in their opinion, the first two authors should be regarded as joint first authors.

\section{REFERENCES}

1 Tiepolo L, Zuffardi O. Localization of factors controlling spermatogenesis in the nonfluorescent portion of the human $Y$ chromosome long arm. Hum Genet 1976;34:119-24.

2 Ma K, Sharkey A, Kirsch S, Vogt P, Keil R, Hargreave TB, McBeath S, Chandley AC. Towards the molecular localisation of the AZF locus: mapping of microdeletions in azoospermic men within 14 subintervals of interval 6 of the human Y chromosome. Hum Mol Genet 1992;1:29-33.

3 Vogt PH, Edelmann A, Kirsch S, Henegariu O, Hirschmann P, Kiesewetter F, Kohn FM, Schill WB, Farah S, Ramos C, Hartmann M, Hartschuh W, Meschede D, Behre HM, Castel A, Nieschlag E, Weidner W, Grone HJ, Jung A, Engel W, Haidl G. Human Y chromosome azoospermia factors (AZF) mapped to different subregions in Yq11. Hum Mol Genet 1996;5:933-43.

4 Kuroda-Kawaguchi T, Skaletsky H, Brown LG, Minx PJ, Cordum HS, Waterston RH, Wilson RK, Silber S, Oates R, Rozen S, Page DC. The AZFc region of the $Y$ chromosome features massive palindromes and uniform recurrent deletions in infertile men. Nat Genet 2001;29:279-86.

5 Reijo R, Lee TY, Salo P, Alagappan R, Brown LG, Rosenberg M, Rozen S, Jaffe T, Straus D, Hovatta O, Delachapelle A, Silber S, Page DC. Diverse spermatogenic defects in humans caused by $Y$ chromosome deletions encompassing a novel RNA-binding protein gene. Nat Genet 1995; 10:383-93

6 Vogt PH. Human chromosome deletions in $\mathrm{Yql} 1$, AZF candidate genes and male infertility: history and update. Mol Hum Reprod 1998;4:739-44.

7 Seboun E, Barbaux S, Bourgeron T, Nishi S, Agulnik A, Egashira M, Nikkawa N, Bishop C, Fellous M, McElreavey K, Kasahara M, Algonik A Gene sequence, localization, and evolutionary conservation of DAZLA, a candidate male sterility gene. Genomics 1997;41:227-35

8 Lahn BT, Tang ZL, Zhou J, Barndt RJ, Parvinen M, Allis CD, Page DC Previously uncharacterized histone acetyltransferases implicated in mammalian spermatogenesis. Proc Natl Acad Sci U S A 2002;99:8707-12.

9 Dorus S, Gilbert SL, Forster ML, Barndt RJ, Lahn BT. The CDY-related gene family: coordinated evolution in copy number, expression profile and protein sequence. Hum Mol Genet 2003;12:1643-50.

10 Chang PL, Sauer MV, Brown S. Y chromosome microdeletion in a father and his four infertile sons. Hum Reprod 1999;14:2689-94.
11 Gatta V, Stuppia L, Calabrese G, Morizio E, Guanciali-Franchi P, Palka G. A new case of Yq microdeletion transmitted from a normal father to two infertile sons. J Med Genet 2002;39:e27.

12 Saut N, Terriou P, Navarro A, Levy N, Mitchell MJ. The human Y chromosome genes $B P Y 2, C D Y 1$ and DAZ are not essential for sustained fertility. Mol Hum Reprod 2000;6:789-93.

13 Bienvenu T, Patrat C, McElreavey K, de Almeida M, Jouannet P. Reduction in the DAZ gene copy number in two infertile men with impaired spermatogenesis. Ann Genet 2001:44:125-8.

14 de Vries JW, Hoffer MJ, Repping S, Hoovers JM, Leschot NJ, van der Veen F. Reduced copy number of DAZ genes in subfertile and infertile men. Fertil Steril 2002;77:68-75.

15 Fernandes S, Huellen K, Goncalves J, Dukal H, Zeisler J, Rajpert De Meyts E, Skakkebaek NE, Habermann B, Krause W, Sousa M, Barros A, Vogt PH. High frequency of DAZ1/DAZ2 gene deletions in patients with severe oligozoospermia. Mol Hum Reprod 2002;8:286-98.

16 Repping S, Skaletsky H, Brown L, van Daalen SK, Korver CM, Pyntikova T, Kuroda-Kawaguchi T, de Vries JW, Oates RD, Silber S, van der Veen F, Page DC, Rozen S. Polymorphism for a 1.6-Mb deletion of the human $Y$ chromosome persists through balance between recurrent mutation and haploid selection. Nat Genet 2003;35:247-51

17 Yen P. The fragility of fertility. Nat Genet $2001 ; 29: 243-4$

18 Saxena R, de Vries JW, Repping S, Alagappan RK, Skaletsky H, Brown LG, Ma P, Chen E, Hoovers JM, Page DC. Four DAZ genes in two clusters found in the AZFc region of the human Y chromosome. Genomics 2000;67:256-67.

19 Brownstein MJ, Carpten JD, Smith JR. Modulation of non-templated nucleotide addition by Taq DNA polymerase: primer modifications that facilitate genotyping. Biotechniques 1996;20:1004-6.

20 Skaletsky H, Kuroda-Kawaguchi T, Minx PJ, Cordum HS, Hillier L, Brown LG, Repping S, Pyntikova T, Ali J, Bieri T, Chinwalla A, Delehaunty A, Delehaunty K, Du H, Fewell G, Fulton L, Fulton R, Graves T, Hou SF, Latrielle P, Leonard S, Mardis E, Maupin R, McPherson J, Miner T, Nash W, Nguyen C, Ozersky P, Pepin K, Rock S, Rohlfing T, Scott K, Schultz B, Strong C, TinWollam A, Yang SP, Waterston RH, Wilson RK, Rozen S, Page DC. The malespecific region of the human $Y$ chromosome is a mosaic of discrete sequence classes. Nature 2003;423:825-37.

21 Jobling MA, Samara V, Pandya A, Fretwell N, Bernasconi B, Mitchell RJ, Gerelsaikhan T, Dashnyam B, Sajantila A, Salo PJ, Nakahori Y, Disteche CM, Thangaraj K, Singh L, Crawford MH, Tyler-Smith C. Recurrent duplication and deletion polymorphisms on the long arm of the $Y$ chromosome in normal males. Hum Mol Genet 1996;5:1767-75.

22 Hammer MF, Horai S. Y chromosomal DNA variation and the peopling of Japan. Am J Hum Genet 1995:56:951-62.

23 Hurles ME, Irven C, Nicholson J, Taylor PG, Santos FR, Loughlin J, Jobling MA, Sykes BC. European Y-chromosomal lineages in Polynesians: a contrast to the population structure revealed by mtDNA. Am J Hum Genet 1998;63:1793-806.

24 Underhill PA, Jin L, Lin AA, Mehdi SQ, Jenkins T, Vollrath D, Davis RW Cavalli-Sforza LL, Oefner PJ. Detection of numerous Y chromosome biallelic polymorphisms by denaturing high-performance liquid chromatography. Genome Res 1997;7:996-1005.

25 Y Chromosome Consortium. A nomenclature system for the tree of human $Y$ chromosomal binary haplogroups. Genome Res 2002;12:339-48.

26 Rosser ZH, Zerjal T, Hurles ME, Adojaan M, Alavantic D, Amorim A, Amos W, Armenteros M, Arroyo E, Barbujani G, Beckman G, Beckman L, Bertranpetit J, Bosch E, Bradley DG, Brede G, Cooper G, Corte-Real HB, de Kniiff P, Decorte R, Dubrova YE, Evgrafov O, Gilissen A, Glisic S, Golge M, Hill EW, Jeziorowska A, Kalaydjieva L, Kayser M, Kivisild T, Kravchenko SA, Krumina A, Kucinskas V, Lavinha J, Livshits LA, Malaspina P, Maria S, McElreavey K, Meitinger TA, Mikelsaar AV, Mitchell RJ, Nafa K, Nicholson J, Norby S, Pandya A, Parik J, Patsalis PC, Pereira L, Peterlin B, Pielberg G, Prata MJ, Previdere C, Roewer L, Rootsi S, Rubinsztein DC, Saillard J, Santos FR, Stefanescu G, Sykes BC, Tolun A, Villems R, Tyler-Smith C, Jobling MA. Y-chromosomal diversity in Europe is clinal and influenced primarily by geography, rather than by language. Am J Hum Genet 2000;67:1526-43

27 Zerial T, Dashnyam B, Pandya A, Kayser M, Roewer L, Santos FR, Schiefenhovel W, Fretwell N, Jobling MA, Harihara S, Shimizu K, Semiidmaa D, Sajantila A, Salo P, Crawford MH, Ginter EK, Evgrafov OV, Tyler-Smith C. Genetic relationships of Asians and Northern Europeans, revealed by Y-chromosomal DNA analysis. Am J Hum Genet 1997:60:1174-83.

28 Fernandes S, Paracchini S, Meyer LH, Floridia G, Tyler-Smith C, Vogt PH. A large AZFc deletion removes DAZ3/DAZ4 and nearby genes from men in $Y$ haplogroup N. Am J Hum Genet 2003;74:180-7.

29 de Vries JW, Repping S, van Daalen SK, Korver CM, Leschot NJ, van der Veen F. Clinical relevance of partial AZFc deletions. Fertil Steril 2002; 78: 1209-14

30 Tilford CA, Kuroda-Kawaguchi T, Skaletsky H, Rozen S, Brown LG, Rosenberg M, McPherson JD, Wylie K, Sekhon M, Kucaba TA, Waterston RH, Page DC. A physical map of the human $Y$ chromosome. Nature 2001;409:943-5.

31 Rozen S, Skaletsky H, Marszalek JD, Minx PJ, Cordum HS, Waterston RH, Wilson RK, Page DC. Abundant gene conversion between arms of palindromes in human and ape $Y$ chromosomes. Nature 2003;423:873-6.

32 Ewis AA, Lee J, Shinka T, Nakahori Y. Microdeletions of a Y-specific marker, $\mathrm{Yfm} 1$, and implications for a role in spermatogenesis. J Hum Genet 2002;47:257-61

33 Kuroki Y, Iwamoto T, Lee J, Yoshiike M, Nozawa S, Nishida T, Ewis AA Nakamura H, Toda T, Tokunaga K, Kotliarova SE, Kondoh N, Koh E, Namiki M, Shinka T, Nakahori Y. Spermatogenic ability is different among males in different $Y$ chromosome lineage. J Hum Genet 1999;44:289-92. 


\section{PostScript}

LETTERS

Correction: no evidence of an association between the T16189C mtDNA variant and late onset dementia (Gibson et al)

We believe that the title of Chinnery et al's paper should be corrected because the data the authors present do not include an analysis of the 16189 variant of mtDNA (Table 1).

We defined the 16189 variant as the DNA sequence associated with a polydC tract, resulting from a $\mathrm{T} 16189 \mathrm{C}$ transition that may generate heteroplasmic length variation, table 1. Heteroplasmic length variation does not occur when the polymeric tract is interrupted by a $\mathrm{c} \rightarrow \mathrm{t}$ transition, which occurs at several different sites but commonly at nucleotice 16186 or 16192 . Individuals with these additional polymorphisms are excluded from our definition of the 16189 variant because they no longer have a long homopolymeric c tract. The variant does not alter any coding sequences yet lies near to mtDNA control sequences, which can explain its effects on mitochondrial function. In studies of disease associations with variants in this region we chose to investigate the 16189 variant rather than any other sequence change, because of the likely functional effects of the homopolymeric $\mathrm{C}$ tract and heteroplasmic length variation.

Gibson et al ${ }^{1}$ have shown that the overall prevalence of the T16189C allele in their population is $12.6 \%$, which is substantially higher than the $6.4-8.8 \%$ prevalence of the 16189 variant reported in other studies. ${ }^{23}$ This is because they have quantfied the prevalence of the T16189C transition per se rather than the variant. Including these additional polymorphisms may dilute out a real association with the 16189 variant. The authors have shown that the $\mathrm{T} 16189 \mathrm{C}$ transition per se is not a risk factor for late onset dementia, ${ }^{1}$ but to our knowledge this has not, in any case, been implicated with any disease phenotypes. However, they found that the heteroplasmic length variation, which implies the presence of the 16189 variant, was associated with a 2.2 fold increased risk. They did not, however, quantify the relative risk for the 16189 variant per se, which could well be significant, in direct contradiction of their title. From their data, it is possible that the variant might in fact predispose to late onset dementia.

The 16189 variant is a risk factor for type 2 diabetes, ${ }^{4}$ thinness at birth, ${ }^{5}$ and aged 20 years $^{6}$ iron loading in haemochromato-

Table 1 Sequences of identified variants

\begin{tabular}{ll}
\hline Variant & Nucleotides \\
\hline Wild type sequence & ccccctcccc \\
$\begin{array}{l}\text { Sequences included in } \\
\text { Chinnery's analysis }\end{array}$ & $\begin{array}{l}\text { ccccccctcc } \\
\text { cctccccccc } \\
\text { ccccccccc etc } \\
\text { cccccccccc }\end{array}$ \\
$\begin{array}{l}\text { 16189 variant } \\
\text { Heteroplasmic length } \\
\text { variants included } \\
\text { within 16189 variant }\end{array}$ & $\begin{array}{l}c c c c c c c c c \\
\text { cccccccccc etc }\end{array}$ \\
\hline
\end{tabular}

sis, ${ }^{7}$ dilated cardiomyopathy, ${ }^{8}$ endometrial cancer, ${ }^{9}$ and other multifactorial disorders. ${ }^{10}$ This variant may be mildly detrimental. ${ }^{11}$ Unlike many other mtDNA polymorphisms implicated in type 2 diabetes, this variant probably has bona fide functional consequences because it has arisen many times independently in the various populations studied, ${ }^{2412}$ excluding a founder effect. Because the authors did not perform mitochondrial haplotyping ${ }^{1}$ to exclude a founder effect, their results may reflect the consequences of other co-segregating genes.

J Poulton, S Das

Nuffield Department of Obstetrics and Gynaecology, University of Oxford, Women's Centre, John Raddliffe Hospital, Oxford, UK

Correspondence to: Professor J Poulton, Nuffield Department of Obstetrics and Gynaecology, University of Oxford, Women's Centre, John Raddliffe Hospital, Oxford, OX3 9DU, UK; joanna.poulton@ obs-gyn.ox.ac.uk

doi: 10.1136/jmg.2004.019208

Received 13 February 2004

Accepted for publication 29 May 2004

Conflict of interest: none declared

\section{References}

1 Gibson AM, Edwardson JA, Turnbull DM, McKeith IG, Morris CM, Chinnery PF. No evidence of an association between the T16189C m+DNA variant and late onset dementia. J Med Genet 2004:41:e7.

2 Poulton J, Marchington D, Brown MS, Phillips D, Hagelberg E. Does a common mitochondrial DNA polymorphism underlie susceptibility to diabetes and the thrifty genotype? Trends Genet 1998; 14:385-7.

3 Miller K, Dawson J, Hagelberg E. A concordance of nucleotide substitutions in the first and second hypervariable segments of the human m+DNA control region. Int J Legal Med 1996;109:107-13.

4 Poulton J, Luan J, Macaulay V, Hennings S, Mitchell J, Wareham NJ. Type 2 diabetes is associated with a common mitochondrial variant: evidence from a population-based case-control study. Hum Mol Genet 2002;11:1581-3.

5 Casteels K, Ong K, Phillips D, Bendall H, Pembrey M. Mitochondrial 16189 variant, thinness at birth, and type-2 diabetes. ALSPAC study team. Avon Longitudinal Study of Pregnancy and Childhood Lancet 1999:353:1499-500.

6 Poulton J, Macaulay V, Livesey K, Wareham N, Parker E, Phillips D, Simmons D, Mayosi B, Knogali S, Robson KA. A common mtDNA variant may be a susceptibility factor in 4 important multifactorial conditions. Am J Hum Genet 2001;69(Suppl):579.

7 Livesey KJ, Wimhurst VL, Carter K, Worwood M, Cadet E, Rochette J, Roberts AG, Pointon JJ, Merryweather-Clarke AT, BassettML, Jovanolle AM, Mosser A, David V, Poulton J, Robson KJ. The 16189 variant of mitochondrial DNA occurs more frequently in C282Y homozygotes with haemochromatosis than those without iron loading. J Med Genet 2004:41:6-10.

8 Khogali S, Mayosi B, Beattie J, McKenna W Watkins $\mathrm{H}$, Poulton J. A common mitochondrial DNA D-loop variant is associated with idiopathic dilated cardiomyopathy in two different populations. Lancet 2001;357:1265-7.

9 Liu VW, Wang Y, Yang HJ, Tsang PC, Ng TY, Wong LC, Nagley P, Ngan HY. Mitochondrial DNA variant $16189 T \rightarrow C$ is associated with susceptibility to endometrial cancer. Hum Mutat 2003:22:173-4.

10 Momiyama Y, Furutani M, Suzuki Y, Ohmori R, Imamura S, Mokubo A, Asahina T, Murata C, Kato K, Anazawa S, Hosokawa K, Atsumi Y,
Matsuoka K, Kimura M, Kasanuki H, Ohsuzu F, Matsuoka R. A mitochondrial DNA variant associated with left ventricular hypertrophy in diabetes. Biochem Biophys Res Commun 2003;312:858-64.

11 Morten K, Jen C, Poulton J. The 16189 variant of mtDNA in type 2 diabetes: towards a molecular mechanism. Diabet Med 2003;20(Suppl 2):13.

12 Poulton J, Bednarz AL, Scott-Brown M, Thompson C, Macaulay VA, Simmons D. The presence of a common mitochondrial DNA variant is associated with fasting insulin levels in Europeans in Auckland. Diabet Med 2002:19:969-71.

\section{No evidence of an association between the mtDNA 16184-93 polyC tract and late onset dementia}

We are grateful to Professor Poulton and Dr Das for clarifying their definition of the 16189 variant. In our study we determined the allele status at position 16189 of mitochondrial DNA (mtDNA), and found no evidence of an association between the 16189C polymorphic sequence variant and late onset dementia. The title of our manuscript therefore reflects our observations and does not need to be corrected. Part of the confusion seems to have arisen because of different definitions of the "16189 variant" in the literature.

The standard "Cambridge" reference mtDNA sequence ${ }^{23}$ has a run of cytosine residues from nucleotide position (np) 16184 to 16193 interrupted by a thymidine residue at nucleotide position 16189. In approximately $12 \%$ of the UK population, there is a $\mathrm{T} \rightarrow \mathrm{C}$ substitution at $\mathrm{np}$ 16189. ${ }^{1}$ In most individuals this results a tract of $10 \mathrm{C}$ residues (polyC tract). This sequence is unstable and is associated with length variation of the polyC tract, probably because of slippage during genome replication, ${ }^{4}$ generating larger and smaller polyC tracts within the same individual during life (heteroplasmy). ${ }^{4}$ However, occasional individuals have other polymorphisms between np 16184 and 16193, which appear to stabilise the tract and do not lead to the generation of length variants. ${ }^{4}$ We suggest a more accurate definition should be used when referring to the homopolymeric $\mathrm{C}$ tract that is present in the majority of individuals with the T16189C substitution. The term "mtDNA 16184-93 polyC tract" will hopefully prevent confusion in the future.

Poulton and Das comment on the results of our logistic regression analysis (table 1 in our paper $\left.^{1}\right)$, and suggest that individuals with homopolymeric tract length heteroplasmy have a 2.2 fold increased risk of developing Alzheimer's disease (AD) compared with controls. This would imply an association between their definition of the 16189 variant and late onset dementia. However, the confidence intervals for the relative risk of 2.2 are 0.85 to 5.81 , comfortably including 1 . The relative risk is therefore not statistically significant and does not support a link between AD and homopolymeric length tract heteroplasmy.

In our original study, ${ }^{1}$ we measured homopolymeric tract length heteroplasmy using a trimmed PCR approach with a fluorescent forward primer. However, not all individuals with a 16184-93 polyC tract also have length heteroplasmy. Therefore, to address the concerns of Poulton and Das experimentally, we directly sequenced the relevant region of 
Table 1 Frequency of the mtDNA $16184-93$ polyC tract in control individuals, patients with dementia with Lewy bodies (DLB) and Alzheimer's disease (AD)

\begin{tabular}{|c|c|c|c|c|}
\hline \multirow[b]{2}{*}{ Group } & \multicolumn{2}{|c|}{$\begin{array}{l}\text { Frequency of the mtDNA } \\
16184-93 \text { polydC tract }\end{array}$} & \multicolumn{2}{|c|}{ Comparison with controls } \\
\hline & $n$ & $\%\left(95 \% \mathrm{Cl}^{*}\right)$ & Odds ratio $(95 \% \mathrm{Cl})$ & pt \\
\hline Controls $(n=129)$ & 9 & 6.98 (3.24 to 12.83 ) & - & - \\
\hline $\mathrm{DLB}(n=97)$ & 10 & 10.31 (5.06 to 18.14 ) & 1.53 (0.60 to 3.93$)$ & 0.46 \\
\hline$A D(n=182)$ & 11 & 6.04 (3.06 to 10.56 ) & 0.85 (0.34 to 2.13$)$ & 0.81 \\
\hline
\end{tabular}

*Exact 95\% confidence intervals for the percentage were calculated using the method of Clopper and Pearson. †Fisher's two tailed exact test. Cl, confidence interval. Each group corresponds to the cohort of neuropathologically confirmed cases and controls reported in our paper.[1] Note that table 2 of our original report[1] only includes subjects where the complete APOE genotype was also known. This data was not available for two controls, one DLB case, and eight $A D$ cases. The data from these cases are included in this table.

mtDNA in all of the cases and controls that harboured the $16189 \mathrm{C}$ variant in our original study, ${ }^{1}$ using an established protocol. ${ }^{5}$ The frequency of the mtDNA 16184-93 polyC tract in our original control population corresponded to values reported in other studies ${ }^{6}$ (table 1); $59 \%$ of control individuals with the T16189C polymorphic variant had a 16184-93 polyC tract, corresponding to publicly available control sequence data (http://www.genpat.uu.se/mtDB/). We found no evidence of an association between $\mathrm{AD}$ or dementia with Lewy bodies and 16184-93 polydC tract in a cohort or neuropathologically defined cases and controls, either by logistic regression analysis, or by directly comparing cases and controls with Fisher's exact test (table 1).

\section{Acknowledgements}

D M Turnbull and P F Chinnery receive support from the Wellcome Trust and the Alzheimer's Research Trust.

\section{S M Keers, A M Gibson, D M Turnbull,} P F Chinnery

Correspondence to: Dr P F Chinnery, Department of Neurology, The Medical School, Framlington Place, Newcastle Upon Tyne, NE2 4HH, UK; p.f.chinnery@

ncl.ac.uk

doi: 10.1136/jmg.2004.022467

Received 5 May 2004

Accepted for publication 9 May 2004

Conflict of interest: none declared

\section{References}

1 Gibson AM, Edwardson JA, Turnbull DM, McKeith IG, Morris CM, Chinnery PF. No evidence of an association between the T16189C mtDNA variant and late onset dementia. J Med Genet 2004;41:e7.

2 Anderson S, Bankier AT, Barrell BG, de Bruijn MH, Coulson AR, Drouin J, Eperon IC Nierlich DP, Roe BA, Sanger F, Schreier PH, Smith AJ, Staden R, Young IG. Sequence and organization of the human mitochondrial genome. Nature 1981;290:457-65.

3 Andrews RM, Kubacka I, Chinnery PF, Lightowlers RN, Turnbull DM, Howell N. Reanalysis and revision of the Cambridge reference sequence for human mitochondrial DNA. Nat Genet 1999;23:147.

4 Howell N, Smejkal CB. Persistent heteroplasmy of a mutation in the human mtDNA control region: hypermutation as an apparent consequence of simple-repeat expansion/contraction. Am J Hum Genet 2000;66:1589-98.

5 Taylor RW, Taylor GA, Durham SE, Turnbull DM. The determination of complete human mitochondrial DNA sequences in single cells: implications for the study of somatic mitochondrial DNA point mutations. Nucleic Acids Res 2001 ;29:E74-4.
6 Khogali SS, Mayosi BM, Beattie JM, McKenna WJ, Watkins H, Poulton J. A common mitochondrial DNA variant associated with susceptibility to dilated cardiomyopathy in two different populations. Lancet 2001;357:1265-7.

7 Livesey KJ, Wimhurst VL, Carter K, Worwood M, Cadet E, Rochette J, Roberts AG, Pointon JJ, Merryweather-Clarke AT, Bassett ML, Jouanolle AM, Mosser A, David V, Poulton J, Robson KJ. The 16189 variant of mitochondrial DNA occurs more frequently in C282Y homozygotes with haemochromatosis than those without iron loading. J Med Genet 2004;41:6-10.

\section{BOOK REVIEWS}

\section{Statistical Methods in Genetic Epidemiology}

By D C Thomas. Oxford University Press, 2004 $\$ 42.50$, pp 435. ISBN 0-19-515939-X

The contemporary research principles of genetic epidemiology are outlined in this book. The author clearly explains the research methodology and statistical analyses required to investigate important genetic epidemiological research questions. These include the following questions: Does a disease cluster in families? (familial aggregation); How does a disease cluster in families? (segregation analysis); Can familial aggregation be explained by genetic or environmental factors? (gene-environment interaction); Can we localise the genetic defect? (linkage and association studies). The theory is mainly illustrated with examples on the genetic epidemiology of cancer. As genetic epidemiology is a hybrid discipline, basic chapters on molecular genetics, epidemiology, statistics, and population genetics are included for those readers who need an introduction to any of these topics.

This book fascinates me because of its high didactic quality. The text is well organised and is easy to read. The content is interesting both to novices and to more advanced readers. The strength of the book is that it gives a complete overview of the different methods used in genetic epidemiology. Owing to its completeness, I would not be surprised if it were used in many semesters or courses on genetic epidemiology around the world. I would expect it also be very useful for the more advanced genetic epidemiologist as an up to date reference text. Readers interested in closely related disciplines such as population genetics, molecular genetics, behaviour genetics, statistical genetics, genomics, and bioinformatics will not find enough detail here and should look elsewhere.
I consider this text to be a standard work in genetic epidemiology and would advise both teachers and researchers in the field to read and use it.

M P Zeegers

\section{Human Evolutionary Genetics: Origins, Peoples \& Disease}

Edited by M A Jobling, M E Hurles, C TylerSmith. Garland Science, 2003, £35.00 pp 458. ISBN 9-780815-341857

With the near completion of the human genome sequence, and the exponential increase in associated information on inter-individual variability, there are enormous opportunities for using these data. Evolutionary geneticists are attempting to understand our origins and revisit the questions of the relative role of selection and drift. For medical geneticists, the search is now on for the genetic causes of complex disease, while forensic science is increasingly exploiting our interindividual differences to solve crimes. All these topics are inextricably linked. This super textbook covers almost everything an undergraduate student in human genetics would need as a basis for any of these areas, but will in fact have a much wider readership. It starts as far back as the structure of DNA, chromosome structure, meiosis, mitosis, and so on, while covering in some depth anthropological and archaeological evidence for the origins of modern humans, the extent and nature of genomic variation, and the principles of human population genetics. It explains clearly how the genome can be considered in blocks, owing to the pattern of historic and prehistoric recombinations and that these pieces of DNA, as well as the Y chromosome and mitochondrial DNA, track back to many ancestors who may have lived in different parts of the world.

This publication is timely, up to date, and has enormous and comprehensive coverage, without being too heavy to carry or costing too much. It is more than just a textbook, because, by using opinion boxes, it discusses contentious and problem issues. Thus as well as providing factual information, the book will stimulate the undergraduate to appraise observations and their interpretation critically. An important example is the discussion of error rates, and the potential impact of errors on interpretation of data. It answers questions that many of us get asked by our non-genetics friends, such as what exactly do we mean when we say that there is $1-2 \%$ sequence difference between humans and chimpanzees? How much do the different population groups of the world differ and is the term race meaningful? Clearly, as far as humans are concerned, it is not.

The book will also serve as a very useful introduction to molecular and population genetics for epidemiologists, anthropologists, and others who are new (or indeed not so new) to the field. It contains a wealth of information relevant for medical geneticists who are embarking on association studies. This, for example, includes the effects of selection and the effects of population admixture.

The book is very well laid out, with chapters grouped in six main sections, each of which aims to answer a question (Why study evolutionary genetics? How do we study genome diversity? How do we interpret genetic variation? Where and when did humans originate? How did humans colonise the world? How is an evolutionary perspective helpful?) There is a 
good index and glossary, so that it is easy to look things up, and there are extensive references at the end of each chapter and recommendations for further reading. Indeed there are but few short-comings. The figures and tables, which are on the one hand very useful and informative, do also have some weaknesses. Whether it is my failing eyesight or heterozygous manifestation of a colour vision anomaly, I often found the blue grey and black shadings and characters extremely difficult to distinguish. The figure legends could also sometimes have been more informative. However Mark Jobling and colleagues are to be congratulated-this book is a good buy, an excellent read, and is to be strongly recommended.

\section{M Swallow}

\section{CORRECTIONS}

doi: 10.1136/jmg.2004.020644corr l

In the paper Recent advances in understanding haemochromatosis: a transition state (JMG 2004;41:72l-30) figures 1 and 2 were incorrect. Below are the corrected figures.

$\mathrm{Al76CV}$ has been changed to Al76V and R224G has been changed to R224Q in figure 1 .

N114D has been changed to N144D in figure 2. The journal apologises for these errors.

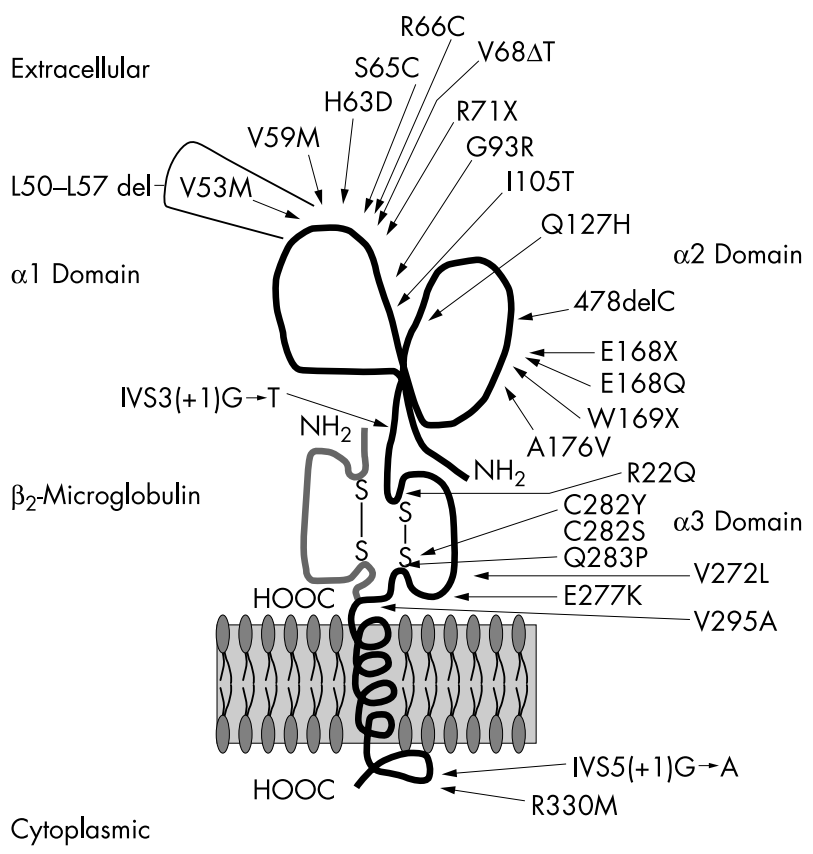

Figure 1

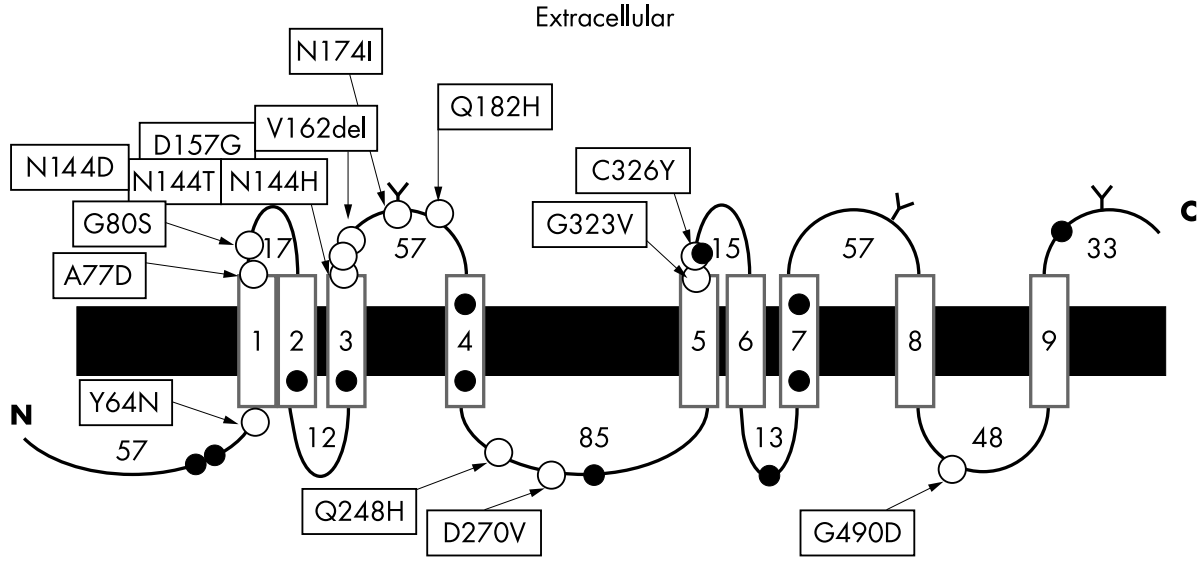

Cytoplasmic

Figure 2 
doi: 10.1136/jmg.2004.022111 corr l

In the paper Recent advances (JMG 2004; 41:814-25) figure 2 was incorrect. Below is the corrected figures.

A small black bar has been inserted on the line representing the deletion present in the patient number 3273 . The author apologies for this error.

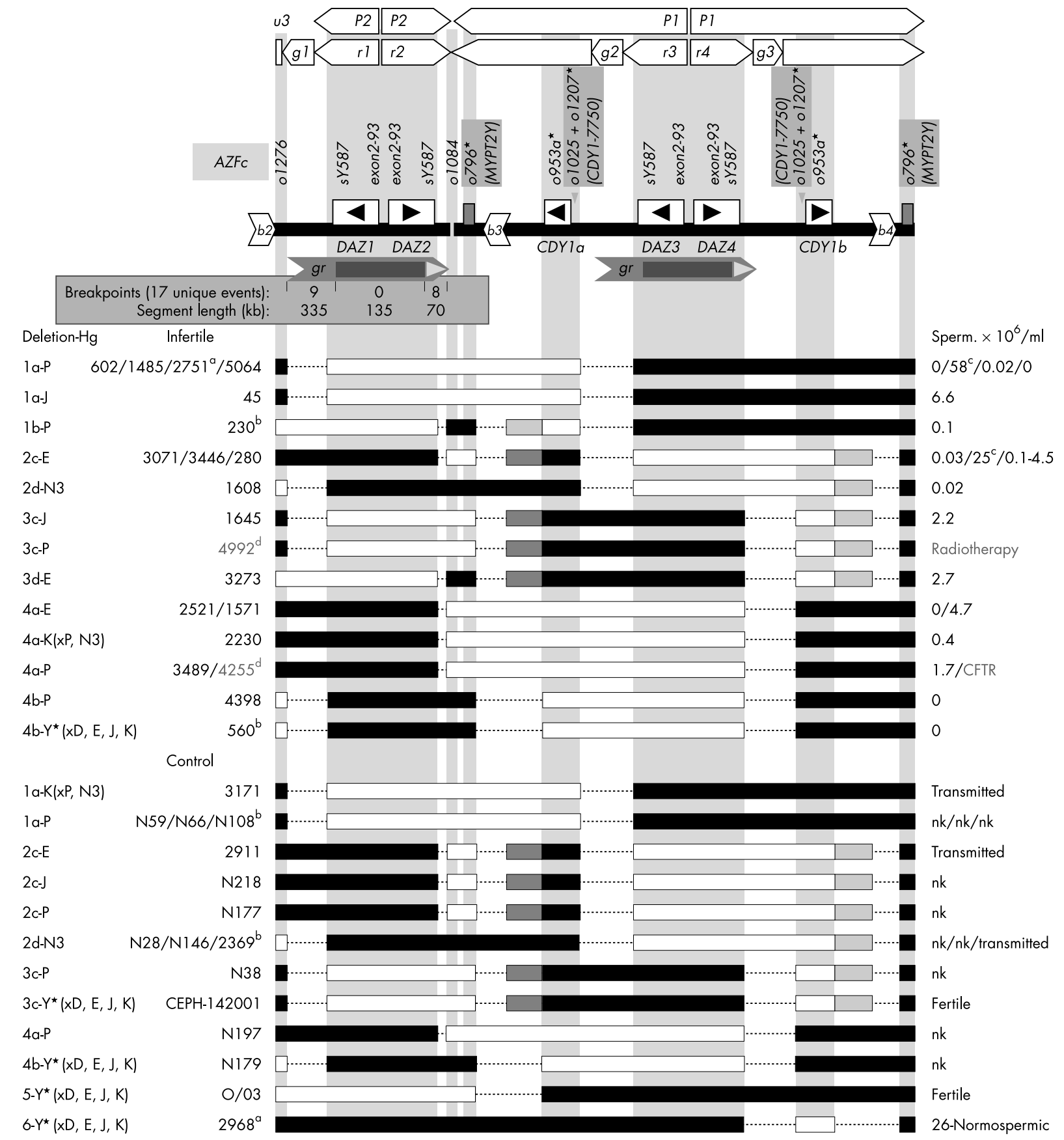

Figure 2 